\title{
LeChatelier-Samuelson principle in games and pass-through of shocks
}

Alexei Alexandrov, Consumer Financial Protection Bureau

Özlem Bedre-Defolie, ESMT European School of Management and Technology 


\title{
LeChatelier-Samuelson principle in games and pass-through of shocks
}

\author{
Alexei Alexandrov** Özlem Bedre-Defolie ${ }^{\ddagger}$
}

November 19, 2015

\begin{abstract}
The LeChatelier-Samuelson principle ("the principle") states that as a reaction to a shock, an agent's short-run adjustment of an action is smaller than the long-run adjustment of that action when the other related actions can also be adjusted. We extend the principle to strategic environments and to shocks that affect more than one action directly. We define long run as an adjustment that also includes the affected player adjusting its other actions and other players adjusting their strategies. We show that the principle holds for 1) supermodular games (strategic complements), 2) submodular games (strategic substitutes) for shocks that affect only one player's action directly and when the players' payoffs depend only on their own strategies and the sum of the rivals' strategies (for example, homogeneous Cournot oligopoly). We also provide other sufficient conditions for the principle to hold in games of strategic substitutes. Our results imply that when the principle holds a multiproduct oligopoly might have lower cost pass-through in the short run than in the long run. Hence, we argue that the principle might explain the empirical findings of overshifting of cost and unit tax by multiproduct firms.
\end{abstract}

\section{Introduction}

The LeChatelier-Samuelson principle ("the principle") states that when an agent (firm/consumer) experiences a shock to an exogenous parameter (e.g., cost), the agent's short-run adjustment of a decision variable (e.g., quantity demanded) is smaller than the long-run adjustment of that variable when the other endogenous variables can also be adjusted. Paul Samuelson introduced the principle to economics and applied it to argue that the long-run elasticity of demand/supply is higher in magnitude than the short-run elasticity, a conjecture that dates back to at least Alfred Marshall 1

${ }^{*}$ Consumer Financial Protection Bureau, alexei.alexandrov@cfpb.gov. The views expressed are those of the authors and do not necessarily represent those of the Director of the Consumer Financial Protection Bureau nor those of the staff.

${ }^{\dagger}$ European School of Management and Technology (ESMT), Berlin, ozlem. bedre@esmt.org

${ }^{\ddagger}$ We thank to Rabah Amir, Paul Heidhues, Emanuel Tarantino, and the participants of "Workshop on Multiproduct Firms in Industrial Organization and International Trade," Bad Homburg, for their helpful comments.

${ }^{1}$ Samuelson singled out the principle as one of the major contributions of Samuelson 1947], see the preface of the book's second (paperback) edition from 1965. See also Samuelson 1960, and Kusumoto [1976]. 
In other words, when the principle fails to hold, the long-run demand (supply) is actually less elastic than the short-run demand (supply).

The original application of the principle is a firm adjusting its labor to a wage change in the short run, and then in the long run the firm can also adjust its capital, inducing further adjustment of labor. Suppose that the shock is a wage increase that leads to a short-run decrease in labor. If the inputs are complements (supermodular), then the short-run decrease in labor causes a longrun decrease in capital, that in turn causes an even further decrease in labor. If the inputs are substitutes (submodular), then the short-run decrease in labor causes a long-run increase in capital, that in turn causes an even further decrease in labor: in this context, the principle works regardless of whether the inputs are complements or substitutes.

The principle is originally defined for a non-strategic agent facing an idiosyncratic shock, which affects directly only one endogenous variable (or action) and the other related actions are affected indirectly due to changes in the directly affected action. We extend the principle to strategic environments and to covariant shocks, which affect more than one action directly ${ }^{2}$ In our framework the short-run adjustment of a directly affected action involves only that action being adjusted and the long-run adjustment also incorporates the feedback effects from the adjustments of other related actions by the same player or by other players 3 To rule out cases where anything can happen, we only consider covariant shocks that directly affect actions in the same way. For example, an industry-wide tax increase directly induces each firm to increase its price. Note that we allow for the indirect effect of the rivals increasing their prices to possibly counteract the direct effect. We identify two key factors for the applicability of the principle in general: 1) whether actions are supermodular or submodular, and 2) if they are submodular, whether the shock is idiosyncratic or covariant.

Our focal application is cost pass-through. The pass-through of cost shocks on prices is important for multitude of economic problems varying from tax incidence: the allocation of tax burden between firms and consumers ${ }^{4}$ and the effects of any shock changing firms' costs, such as macroeconomic shocks 5 , mergers ${ }^{6}$ and regulations. $]^{7}$

Empirical literature documents that in a variety of settings retail cost pass-through rates are

\footnotetext{
${ }^{2}$ For instance, in single-product oligopoly a firm specific cost shock is an idiosyncratic shock, whereas an industrywide tax increase is a covariant shock.

${ }^{3}$ In this paper the difference between short-run versus long-run does not have to arise from dynamic adjustments to the initial shock. We use this terminology following the LeChatelier literature, while noting that these definitions are made mainly to analyze when accounting for feedback effects from other actions might increase the adjustment of a directly affected action.

${ }^{4}$ See, for example, Keen 1998, Anderson, De Palma, and Kreider 2001, and Weyl and Fabinger 2013.

${ }^{5}$ See, for example, Goldberg 1995 and Goldberg and Verboven 2001 on exchange rate pass-through.

${ }^{6}$ The effects of a merger depend on the pass-through of cost efficiencies to consumers, pass-through of wholesale price changes to final prices (relevant both for upstream mergers and downstream mergers. See, for example, Farrell and Shapiro 2010, Jaffe and Weyl 2013.

'For instance, the Durbin amendment of the U.S. 2010 Dodd-Frank Act regulated debit card interchange fees that are paid by the merchant's bank to the cardholder's bank for every transaction, and so the regulation changed the effective variable costs of these banks, see Kay, Manuszak, and Vojtech 2014], see also Agarwal, Chomsisengphet, Mahoney, and Stroebel 2015. for an application in the U.S. credit card market.
} 
either close to 1 (100\% pass-through or full cost shifting) or are above one (overshifting) 8 Similarly, firm-specific costs are nearly fully shifted or overshifted on prices by multiproduct retailers 99 In particular, Berck, Leibtag, Solis, and Villas-Boas 2009] analyze pass-through of commodity prices onto retail prices (of cereal and chicken), and find that the short-run pass-through rates are below one, while the long-run pass-through rates (accounting for lagged effects) of two commodity prices are above one. Existing theories explain overshifting of costs by sufficiently convex demand or sufficiently concave costs 10 For instance, a single-product monopoly with constant returns to scale and linear demand has a cost pass-through rate of 50\%. For linear cost, the cost pass-through rate is predicted to be below one for most common demand functions (those generated by Normal, Logistic, Type I Extreme Value, Laplace, Type III Extreme Value distributions, see Weyl and Fabinger 2013).

We provide a theoretical explanation for why a multiproduct monopoly or oligopoly might have lower (short-run) cost pass-through when only the directly affected product's price is adjusted than the (long-run) cost pass-through after accounting for adjustments of all related products sold by the same firm or by other firms. In particular, the long-run cost pass-through can be above one under less restrictive conditions than the short-run pass-through. We illustrate this by studying under which conditions the LeChatelier-Samuelson principle extends to strategic environments and to covariant shocks. For instance, a product specific tax changes the optimal prices of a twoproduct firm selling demand/cost related products directly, and so it is a covariant shock 11 We characterize the conditions that ensure that the long-run cost pass-through of this tax onto the directly affected product is higher than the short-run pass-through. Applications of our theory include multiproduct monopoly selling complements, differentiated Bertrand oligopoly of single product firms, undifferentiated Cournot oligopoly (only for firm specific shocks), differentiated Bertrand oligopoly of multiproduct firms selling complements.

In general, we show that the principle holds if each player's marginal payoff from her actions is increasing in the parameter: 1) both for idiosyncratic and covariant shocks in supermodular games (strategic complements), 2) for idiosyncratic shocks in submodular games (strategic substitutes) where each player's payoff is a function of own strategy and the sum of the others' actions (do not depend on others' actions in another way)- conditions that hold, for example, for undifferentiated Cournot oligopoly, 3) for idiosyncratic shocks in games of strategic substitutes satisfying Morishima

\footnotetext{
${ }^{8}$ See, for example, Young and Bielińska-Kwapisz 2002, Kenkel 2005 for excise taxes on alcohol; see Barzel 1976], Poterba [1996], Genesove and Mullin [1998 for excise taxes on cigarettes, see Besley and Rosen [1999], Bonnet and Réquillart 2013b], Bonnet and Réquillart 2013a] for excise taxes on consumer goods, and see Fullerton and Metcalf 2002 for a review

Besanko, Dubé, and Gupta 2005 use a scanner data of a grocery store, find above one pass-through for nearly half of the product categories they study and also find significant and non-zero cross-product cost pass-through rates. Dubé and Gupta 2008 confirm the latter finding. On the other hand, another line of literature documents that macro-economic cost shocks, like exchange rates, are partially passed onto prices (cost pass-through of below one), in particular, in intermediary product markets (Campa and Goldberg 2005).

${ }^{10}$ See, for example, Stern 1987, Anderson, De Palma, and Kreider 2001, and Weyl and Fabinger 2013.

${ }^{11}$ Suppose a firm is selling products $\mathrm{A}$ and $\mathrm{B}$, that are related either in the demand or in the cost function, and the tax imposed on product A changes. Even if the firm does not change product A's price, the firm would still want to change product B's price, since product A's margin changed.
} 
conditions ${ }^{12}$ The principle might fail to hold in games of strategic substitutes for idiosyncratic shocks (if there are more than two players) or for covariant shocks in games of strategic substitutes or in games of strategic heterogeneity, where for some players the rivals' actions are strategic substitutes and for some players the rivals' actions are strategic complements. We illustrate specific applications of our theory by a simple model of two decisions, including two-product monopoly, single-product duopoly, and discuss implications for pass-through of cost and of a price cap regulation. There we also provide the necessary and sufficient conditions on the demand functions for the principle to hold.

Our results shed light on the principle in general. We argue that what matters is not whether the interactions are strategic, but rather how the interaction between different decisions is structured, regardless of whether the decisions are undertaken by the same agent. In particular, the reasons behind the principle sometimes failing to hold in submodular games, either for idiosyncratic shocks with more than two players or for covariant shocks, are similar to the reasons behind the principle sometimes failing to hold in the aforementioned labor and capital setup. We illustrate specific applications of our theory using a simple model of two decisions, where we also provide a necessary and sufficient condition for the principle to hold when the decisions are not supermodular.

Following Milgrom and Roberts [1996, we derive our general results using the lattice theory approach in Section 2 for supermodular games (Section 2.2) and for submodular games (Section 3). In Section 4, we provide a model of two decision variables using the first-order condition approach, see Suen, Silberberg, and Tseng 2000. In Section 5 we discuss the implications of our theoretical predictions for multiproduct firm cost pass-through, the pass-through of a price cap regulation on unregulated price, cost pass-through rates of a monopoly selling a base product and add-on when add-on prices are not salient to consumers.

\section{LeChatelier-Samuelson Principle in Supermodular Games: Lattice- Theoretic Approach}

\subsection{Mathematical definitions, notation and basic theorems}

A reader who is at least somewhat familiar with the monotone comparative statics literature can safely skip this subsection (2.1).

A partially ordered set (or poset) is a set $S$ on which there is a binary relation $\preceq$ that is reflexive, antisymmetric, and transitive 13 Given $T \subset S, \bar{b} \in S$ is called an upper bound for $\mathrm{T}$ if $x \preceq \bar{b}$ for all $x \in T$ and the smallest upper bound is called the supremum of $\mathrm{T}$ (denoted $\sup (T)$ ). Symmetrically, $\underline{b} \in S$ is called a lower bound for $\mathrm{T}$ if $\underline{b} \preceq x$ for all $x \in T$ and the greatest lower bound is called the infimum of $\mathrm{T}$ (denoted inf $(T)$ ).

The set $S$ is a lattice if for each two point set $\{x, y\} \subset S$, there is a supremum for $\{x, y\}$

\footnotetext{
${ }^{12}$ See Lady and Quirk 2010 and Morishima 1952.

${ }^{13} \mathrm{~A}$ binary relation $\preceq$ on set $\mathrm{S}$ is reflexive if $x \preceq x$ for each $x \in S$, antiasymmetric if $x^{\prime} \preceq x^{\prime \prime}$ and $x^{\prime \prime} \preceq x^{\prime}$ imply $x^{\prime}=x^{\prime \prime}$ for all $x, x^{\prime} \in \bar{S}$, transitive if $x^{\prime} \preceq x^{\prime \prime}$ and $x^{\prime \prime} \preceq x^{\prime \prime \prime}$ imply $x^{\prime} \preceq x^{\prime \prime \prime}$
} 
(denoted $x \vee y$ and called the join of $x$ and $y$ ) and an infimum (denoted $x \wedge y$ and called the meet of $x$ and $y$ ) in $S$. The lattice is complete if for all nonempty subsets $T \subset S, \inf (T) \in S$ and $\sup (T) \in S$. A subset $\mathrm{T}$ of lattice $\mathrm{S}$ is a sublattice of $\mathrm{S}$ if the supremum and infimum of any two elements of $\mathrm{T}$ belong also to $\mathrm{T}$.

Definition 1 (Coordinate-wise order or product order) Let $S_{i}$ be a lattice with binary relation $\preceq$ for all $i=1, . ., N . S=S_{1} X S_{2} X \ldots S_{N}$ has product order if for all $x, x^{\prime} \in S$ with $x^{\prime} \preceq x$ means that $x_{n}^{\prime} \preceq x_{n}$ for all $n \in N$.

Definition 2 (Supermodularity) A function $f: S \rightarrow \Re$ is supermodular if for all $x, y \in S$,

$$
f(x)+f(y) \preceq f(x \wedge y)+f(x \vee y) .
$$

If $S=S_{1} X S_{2}$, where $S_{1}$ and $S_{2}$ are two lattices ordered coordinate-wise, then supermodularity captures the idea of complementarity between $S_{1}$ and $S_{2}$. For instance, if we take $x=\left(x_{1}, x_{2}\right)$ and $y=\left(y_{1}, y_{2}\right)$ such that $x_{1} \succeq y_{1}$ and $y_{2} \succeq x_{2}$, we have $x \vee y=\left(x_{1}, y_{2}\right)$ and $x \wedge y=\left(y_{1}, x_{2}\right)$, then supermodularity implies that

$$
f\left(y_{1}, y_{2}\right)-f\left(y_{1}, x_{2}\right) \preceq f\left(x_{1}, y_{2}\right)-f\left(x_{1}, x_{2}\right) .
$$

that is, the marginal contribution of the second decision from $x_{2}$ to $y_{2}$ increases if we increase the first decision from $y_{1}$ to $x_{1}$. In other words, the marginal contribution of one decision increases in the magnitude of the other decision variable. For functions that are twice differentiable on $\Re^{2}$ supermodularity is equivalent to $\partial^{2} f / \partial x_{1} \partial x_{2} \geq 0$ (Topkis's Characterization Theorem, Topkis [1978]).

Definition 3 (Increasing Differences) Given two lattices $S_{1}$ and $S_{2}$, a function $f: S_{1} X S_{2} \rightarrow \Re$ has increasing differences in its two arguments $x$ and $y$ if for all $x \succeq x^{\prime}$, the difference $f(x, y)-$ $f\left(x^{\prime}, y\right)$ is nondecreasing in $y$.

Supermodularity is a cardinal notion and increasing differences is an ordinal notion 14 Topkis [1978] shows that supermodularity implies increasing differences for a function on a sublattice of the direct product of lattices. However, the converse is not true in general.

Definition 4 (Quasi-supermodularity) A function $f: S \rightarrow \Re$ is quasisupermodular if $f(x) \succeq$ $f(x \wedge y)$ implies $f(x \vee y) \succeq f(y)$ and $f(x) \succ f(x \wedge y)$ implies $f(x \vee y) \succ f(y)$.

Quasi-supermodularity is an ordinal notion and less stronger than cardinal supermodularity, but is in general more demanding than increasing differences. Supermodularity, quasi-supermodularity and increasing differences are equivalent in Euclidian space.

\footnotetext{
${ }^{14}$ If a function is supermodular, the increasing transformation of this function might not be supermodular, so supermodularity is a cardinal notion. However, the property of increasing differences is preserved by the increasing transformation, so is an ordinal notion
} 
Definition 5 (Single Crossing Property) Let $S_{1}$ be a lattice and $S_{2}$ be a partially ordered set, a function $f: S_{1} X S_{2} \rightarrow \Re$ satisfies the single crossing property if for all $x^{\prime} \succ x$ and $y^{\prime} \succ y$, $f\left(x^{\prime}, y\right) \succ f(x, y)$ implies that $f\left(x^{\prime}, y^{\prime}\right) \succ f\left(x, y^{\prime}\right)$, and $f\left(x^{\prime}, y\right) \succeq f\left(x, y^{\prime}\right)$ implies that $f\left(x^{\prime}, y^{\prime}\right) \succeq$ $f\left(x, y^{\prime}\right)$.

The single-crossing property is an ordinal notion and is more general than increasing differences.

Topkis's Monotonicity Theorem Let $S_{1}$ be a lattice and $S_{2}$ be a partially ordered set. Suppose $f(x, y): S_{1} X S_{2} \rightarrow \Re$ is supermodular in $x$ for given $y$ and has increasing differences in $x$ and $y$. Suppose that $y^{\prime} \preceq y$ and that $x \in M \equiv \operatorname{argmax} f(x, y)$ and $x^{\prime} \in M^{\prime} \equiv \operatorname{argmax} f\left(x, y^{\prime}\right)$. Then $x \wedge x^{\prime} \in M^{\prime}$ and $x \vee x^{\prime} \in M$. In particular (when $y=y^{\prime}$ ), the set of maximizers of $f$ is a sublattice.

\subsection{Supermodular Games (Games of Strategic Complementarity)}

We analyze N-player games, where each player has a payoff function $f_{n}\left(x_{n}, x_{-n}, \tau\right)$ such that $x_{n}$ is player $n$ 's strategy belonging to n's strategy set, $S_{n}, x_{-n}$ are the competitors' strategies, and $\tau$ is a parameter in a partially ordered set $T$. Full strategy profile $x=\left(x_{n}, x_{-n}\right)$ belongs to $S=S_{1} X \ldots X S_{N}$. Each strategy set $S_{n}$ has a partial order $\preceq$ and $S$ possess the product order. Let $\Gamma=\left\{N,\left(S_{n}, f_{n}, n \in N\right), \preceq\right\}$ be a game in ordered form. Following Milgrom and Roberts 1990, for each $n \in N$ we assume that

(A1) $S_{n}$ is a complete lattice;

(A2) $f_{n}: S \rightarrow \Re \cup-\infty$ is order upper semi-continuous in $x_{n}$ for fixed $x_{-n}{ }^{15}$ order continuous in $x_{-n}$ for fixed $x_{n}$, and has a finite upper bound;

(A3) $f_{n}$ is supermodular in $x_{n}$ for fixed $x_{-n}$;

(A4) $f_{n}$ has increasing differences in $x_{n}$ and $x_{-n}$;

(A5) $f_{n}$ has increasing differences in $x_{n}$ and $\tau$ for any fixed $x_{-n}$.

The game $\Gamma$ is supermodular under $(\mathrm{A} 1)-(\mathrm{A} 4)$. Let $\overline{B_{n}}\left(x_{-n}, \tau\right)$ be Player n's largest best response and $\underline{B_{n}}\left(x_{-n}, \tau\right)$ be Player n's smallest best response. Theorem 5 of Milgrom and Roberts 1990 show that the largest pure Nash equilibrium, denoted $\overline{X^{*}}(\tau)$, and the smallest pure Nash equilibrium, denoted $\underline{X^{*}}(\tau)$, exist. Let $\overline{X_{n}^{*}}(\tau)$ be Player n's strategy in the largest equilibrium and $X_{n}^{*}(\tau)$ be n's strategy in the smallest equilibrium.

If $f$ function is twice differentiable on an Euclidian interval, Theorem 4 of Milgrom and Roberts [1990] show that supermodularity of decisions of a given player, $x_{n i}$ and $x_{n j}$, (Assumption (A3)) is equivalent to internal strategic complementarity between these decisions (like in Moorthy [2005]) and supermodularity of decisions across players, $x_{n i}$ and $x_{m j}$, (Assumption (A4)), is equivalent to strategic complementarity between rivals' decisions, respectively,

\footnotetext{
${ }^{15} \mathrm{~A}$ chain $C \subset S$ is a totally ordered subset of $\mathrm{S}$, that is, for any $x \in C$ and $y \in C$, either $x \succeq y$ or $y \succeq x$. Given a complete lattice $S$, a function $f: S \rightarrow \Re$ is order continuous if $\lim _{x \in C, x \rightarrow \inf (C)} f(x)=f(\inf (C))$ and $\lim _{x \in C, x \rightarrow \sup (C)} f(x)=f(\sup (C))$. Function $f$ is order upper semi-continous at $x^{\prime}$ if $\lim _{x \rightarrow x^{\prime}} \sup f(x) \preceq f\left(x^{\prime}\right)$.
} 
A3' $\partial^{2} f_{n} / \partial x_{n i} \partial x_{n j} \geq 0$ for all $n$ and all $1 \leq i \leq j \leq k_{n}$,

A4' $\partial^{2} f_{n} / \partial x_{n i} \partial x_{m j} \geq 0$ for all $n \neq m$ and all $1 \leq i \leq k_{n}$ and $1 \leq j \leq k_{m}$.

Following Milgrom and Roberts [1996], we are interested in the difference of adjustment of a given $x_{n}$ to a shift from $\tau$ to $\tau^{\prime}$ such that $\tau \preceq \tau^{\prime}$, where in the short run only $x_{n}$ is adjusting, but the competitors are keeping their choices fixed, and in the long run the competitors adjust $x_{-n}$ as well, in turn inducing a further adjustment in $x_{n}$. Theorem 6 and the following Corollary of Milgrom and Roberts [1990] show that under (A1)-(A5), the largest and smallest pure Nash equilibrium strategies, respectively, $\overline{X_{n}^{*}}(\tau)$ and $X_{n}^{*}(\tau)$, are nondecreasing functions of $\tau$. Using this finding we prove our first result:

Proposition 1 (LeChatelier principle in supermodular games) If a shock increases $\tau$ to $\tau^{\prime}$, under assumptions (A1)-(A5) player n's strategy in the largest Nash equilibrium before the shock is lower than n's short-run best reply (keeping other players' strategies unchanged), which in turn is lower than n's long-run best-reply (accounting for other players' reactions to the shock). Formally,

$$
\overline{X_{n}^{*}}(\tau) \preceq \overline{B_{n}}\left(\overline{X_{-n}^{*}}(\tau), \tau^{\prime}\right) \preceq \overline{X_{n}^{*}}\left(\tau^{\prime}\right)
$$

The same is true for the smallest pure Nash equilibrium and the smallest best response function:

$$
\underline{X_{n}^{*}}(\tau) \preceq \underline{B_{n}}\left(\overline{X_{-n}^{*}}(\tau), \tau^{\prime}\right) \preceq \underline{X_{n}^{*}}\left(\tau^{\prime}\right)
$$

Proof. Since $\overline{X_{n}^{*}}(\tau)$ is the largest pure Nash equilibrium, $\overline{B_{n}}\left(\overline{X_{-n}^{*}}(\tau), \tau\right)=\overline{X_{n}^{*}}(\tau)$. The first inequality is true since $\overline{B_{n}}\left(x_{-n}, \tau\right)$ is nondecreasing in $\tau$ by Topkis's Monotonicity Theorem. Moreover, we have $\overline{X_{-n}^{*}}(\tau) \preceq \overline{X_{-n}^{*}}\left(\tau^{\prime}\right)$ by Milgrom and Roberts [1990] Theorem 6 and the following Corollary. Given that $\overline{B_{n}}\left(x_{-n}, \tau\right)$ is nondecreasing in $x_{-n}$ by Topkis's Monotonicity Theorem and by definition of the new pure Nash equilibrium $\overline{X_{n}^{*}}\left(\tau^{\prime}\right)=\overline{B_{n}}\left(\overline{X_{-n}^{*}}\left(\tau^{\prime}\right), \tau^{\prime}\right)$, the second inequality must also be true. The proof follows the same lines for the smallest pure Nash equilibrium and the smallest best response function.

As most of the monotone comparative statics results, our Proposition applies to only the largest and the smallest pure Nash equilibria. However, Echenique 2002 shows that under certain conditions any non-monotone equilibria in the middle are unstable for adaptive dynamics.

Definition 6 (Idiosyncratic and covariant shocks) We define a shock as idiosyncratic if it directly affects only one decision variable of one player. We define any other shock as "covariant."

In other words, a change in $\tau$ is an idiosyncratic shock to strategy $i$ by player $\mathrm{n}$ if and only if it affects the optimal choice of $x_{n i}$, but does not influence any other actions of player $\mathrm{n}$ or any actions of other players except for through the new optimal $x_{n i}$. If functions $f_{n}$ are differentiable, then a change in $\tau$ is idiosyncratic if and only if $\partial^{2} f_{n} / \partial x_{n i} \partial \tau \neq 0$ for all $j, k, m$, except for $\partial^{2} f_{n} / \partial x_{n i} \partial \tau \neq 0$.

We do not make restrictions on the type of the shock in Proposition 1, and thus it is valid for both types of shocks. To understand the intuition behind Proposition 1 consider an idiosyncratic shock 
increasing the parameter. This has three main effects: the direct effect increases the level of the directly affected strategy of the player (due to A5 we have increasing differences), the non-strategic (or internal) indirect effect increases the level of the other actions made by that player (due to A3 the decisions of a given player are internal strategic complements), and the strategic indirect effect increases the other players' strategies (due to (A4) rivals' strategies are strategic complements). The strategic indirect effect results in a positive feedback loop in supermodular games. However, it might result in a negative feedback loop if rivals' strategies are strategic substitutes, for example, in submodular games, invalidating the principle.

Now, consider a covariant shock directly increasing more than one decision variable of the same or different players. Each direct effect results in indirect effects similar to the previously described ones for a idiosyncratic shock. Non-strategic indirect effects go in the same direction as the direct effect and so result in a positive feedback loop, since internal decisions are strategic complements. Similarly, strategic indirect effects go in the same direction as the direct effect, and so result in a positive feedback loop, as long as the players' strategies are strategic complements. On the other hand, if players' strategies were strategic substitutes, then strategic indirect effects work in the opposite way to the direct effect.

In contrast, suppose that our assumption (A5) is violated: consider a two-player game such that an increase in $\tau$ leads player 1 to increase its strategy, while leading player 2 to decrease its strategy (covariant shock). Then, Proposition 1 (the principle) might not hold since the short-run best reply of player 1 incorporates only its direct reaction to the shock, which is positive, whereas the long-run best reply of player 1 incorporates also the indirect reaction via accounting for the other player's reaction to the shock, which is negative. To rule out cases where anything can happen, as mentioned above, we only analyze covariant shocks that affect all strategies in the same direction 16

Milgrom and Shannon 1994 extend monotone comparative statics results of Milgrom and Roberts 1990 to ordinal conditions. Similarly, we generalize the applicability of the principle from cardinal supermodular games (in the sense of Milgrom and Roberts 1990]) to ordinal supermodular games (in the sense of Milgrom and Shannon [1994]). We assume that:

(Ao1) $S_{n}$ is a compact lattice;

(Ao2) $f_{n}: S \rightarrow \Re \cup-\infty$ is upper semi-continuous in $x_{n}$ for fixed $x_{-n}$, and continuous in $x_{-n}$ for fixed $x_{n}$;

(Ao3) $f_{n}$ is quasisupermodular in $x_{n}$ for fixed $x_{-n}$;

(Ao4) $f_{n}$ satisfies single-crossing property in $\left(x_{n} ; x_{-n}\right)$;

(Ao5) $f_{n}$ satisfies single-crossing property in $\left(x_{n} ; \tau\right)$;

\footnotetext{
${ }^{16}$ In comparison, Samuelson 1947 ruled out covariant shocks completely: "Only imagine a change in a parameter which enters into all of a large number of equilibrium equations causing them simultaneously to shift. The resulting net effect upon our variables could only be calculated as a result of balancing the separate effects..., and for this purpose detailed quantitative values for all the coefficients involved would have to be known."
} 
Under Assumptions (Ao1)-(Ao5) the game is ordinally supermodular. Theorem 13 of Milgrom and Shannon [1994 shows that under Assumptions (Ao1)-(Ao5) the largest and smallest pure Nash equilibrium strategies, denoted respectively $\overline{X_{n}^{*}}(\tau), \underline{X_{n}^{*}}(\tau)$, are monotone nondecreasing functions of parameter $\tau$. Using this result we prove that

Proposition 2 If a shock increases $\tau$ to $\tau^{\prime}$, under assumptions (Ao1)-(Ao5) the result of Proposition 1 holds:

$$
\overline{X_{n}^{*}}(\tau) \preceq \overline{B_{n}}\left(\overline{X_{-n}^{*}}(\tau), \tau^{\prime}\right) \preceq \overline{X_{n}^{*}}\left(\tau^{\prime}\right) .
$$

The same is true for the smallest pure Nash equilibrium and the smallest best response function:

$$
\underline{X_{n}^{*}}(\tau) \preceq \underline{B_{n}}\left(\overline{X_{-n}^{*}}(\tau), \tau^{\prime}\right) \preceq \underline{X_{n}^{*}}\left(\tau^{\prime}\right)
$$

Proof. The proof follows similar lines as the one of Proposition 1 with two differences: we utilize Theorem 4 (Monotonicity Theorem) of Milgrom and Shannon 1994 rather than Topkis' Monotonicity Theorem and use Theorem 13 of Milgrom and Shannon 1994 rather than Theorem 6 of Milgrom and Roberts 1990.

Note that everything in Proposition 2 is set-valued and the inequality signs should be interpreted accordingly to the Veinott's strong set order ${ }^{17}$ The results can be extended even further to allow for the strategy sets to depend on $\tau$, using the results of Jamison 2006. Thus, an increase in the parameter could mean a regulation that deletes some of the strategies from the players' choice sets. See also Quah 2007 and Barthel and Sabarwal 2015] for other potential extensions.

\section{Games with strategic substitutes and strategic heterogeneity}

As we discussed in the previous section, the LeChatelier principle might break down with strategic substitutes. We first illustrate how this can happen for covariant shocks. We also illustrate that having a game that guarantees monotone comparative statics is a necessary, but not a sufficient condition, to ensure that the principle holds. Next we characterize some sufficient conditions under which the principle holds for idiosyncratic shocks. We characterize conditions for covariant shocks in a more restricted two-player setup using first-order approach in Section 4 .

\subsection{Covariant shocks}

We now illustrate with a simple example how the LeChatelier principle can break down for a covariant shock. Suppose that we are analyzing a Cournot duopoly and an increase in the price of oil increases both firms' marginal costs (a covariant shock on $\tau$ ). Further, suppose that the firms are utilizing different technologies: Firm A's production barely relies on oil, and thus an increase

\footnotetext{
${ }^{17}$ Let $S$ be a lattice with relation $\succeq$ and $f$ be a set valued function from $S$ to power set $P(S)$. We say that $X$ is greater than $Y$ according to Veinott's strong set order, that is, $X \succeq Y$, if for every $x \in X$ and for every $y \in Y$, $x \vee y \in X$ and $x \wedge y \in Y$.
} 
in $\tau$ is barely noticeable (at least before Firm B adjusts); however, Firm B's technology heavily relies on oil and an increase in $\tau$ dramatically increases Firm B's marginal cost.

From Firm A's perspective, the short-run adjustment is to slightly decrease the quantity produced. Firm B's adjustment is a combination of two effects: B's quantity slightly increases as a reaction to the small decrease in A's quantity (indirect effect of the shock on B), combined with a significant decrease in B's quantity resulting from B's dramatic cost increase (direct effect of the shock on B), outweighing the indirect strategic effect. But then A's long-run adjustment combines the short-run small quantity decrease (negative direct effect) with the long-run quantity increase (positive indirect effect) due to B's much larger quantity decrease, violating the LeChatelier principle.

The breakdown occurs because the indirect effect of the shock counteracts of the direct effect when players' actions are strategic substitutes. In this example, for firm A the indirect effect dominates the direct effect, but for firm B direct effect dominates the indirect effect.

Roy and Sabarwal 2010 analyze games with strategic substitutes and establish conditions for when a covariant shock leads to all competitors' equilibrium strategies to increase. For each player they require that the direct effect of the shock on that player's optimal strategy dominates the indirect strategic substitute effects arising from the reaction of that firm to all the other firms that modify their optimal strategies as a response to the initial shock. LeChatelier principle breaks down with such an assumption, that is, the long-run change in one player's optimal strategy counteracts with the short-run change even if the direct effects dominate the indirect effects. We further compare our findings to those of Roy and Sabarwal 2010] in Section 4.

Monaco and Sabarwal 2015 analyze games of strategic heterogeneity which are games where for one group of players the strategies of other players are strategic complements (supermodular), while for another group of players the strategies of others are strategic substitutes (submodular). One example is the policing game described in Becker 1968: if criminals increase wrongdoing, then police increases its effort to catch criminals; however, police increasing its effort leads to criminals decreasing wrongdoing. Another example is a differentiated duopoly as in Singh and Vives [1984, where one firm is choosing quantity while the other is choosing price. It is clear that the principle might fail to hold in these contexts as well.

Under Assumptions (Ao1), (Ao2), (Ao3), (Ao5), $\Gamma=\left\{N,\left(S_{n}, f_{n}, n \in N\right), \preceq\right\}$ is a parametrized game of strategic heterogeneity 18 Monaco and Sabarwal 2015 characterize sufficient conditions under which a parametrized game of strategic heterogeneity guarantees monotone comparative statics, that is, the equilibrium strategies increasing in the exogenous parameter.

Suppose that best responses are single-valued. We say that Player $n$ has strategic complements if and only if its best-reply, $B_{n}\left(x_{-n}, \tau\right)$, is increasing in $x_{-n}$. Analogously, Player $n$ has strategic substitutes if and only if $B_{n}\left(x_{-n}, \tau\right)$ is decreasing in $x_{-n}$. Normalize the game so that players $1, \ldots, J$ have strategic substitutes, and the rest, $J+1 \ldots M$, have strategic complements.

\footnotetext{
${ }^{18}$ See Monaco and Sabarwal 2015], p.29, for a more extended definition of parametrized games with strategic heterogeneity.
} 
Let $\overline{x_{n}}=\sup S_{n}$ and define for $\tau^{\prime}>\tau$

- $\widehat{y}_{n}=B_{n}\left(x_{-n}^{*}(\tau), \tau^{\prime}\right)$ for players with strategic substitutes, and

- $\widehat{y}_{n}=B_{n}\left(\left(\widehat{y}_{m}\right)_{m=1}^{J} ;\left(\bar{x}_{m}\right)_{m=J+1, m \neq n}^{M}, \tau^{\prime}\right)$ for players with strategic complements, where $x^{*}(\tau)$ is a Nash equilibrium at $\tau$.

In the following we show that having a game that guarantees monotone comparative statics is not sufficient to ensure that LeChatelier principle holds:

Proposition 3 Under Assumptions (Ao1), (Ao2), (Ao3), (Ao5) if for all players $m=1 \ldots J$ $x_{m}^{*}(\tau) \preceq B_{m}\left(\widehat{y}_{-m}, \tau^{\prime}\right)$ for $\tau^{\prime}>\tau$, then for player $m$ the equilibrium strategy before the shock is lower than the short-run best reply (keeping the other players'strategies constant), which is higher than the long-run best reply (accounting for other players' reactions to the shock), invalidating the LeChatelier principle. Formally,

$$
\begin{aligned}
& x_{m}^{*}(\tau) \preceq B_{m}\left(x_{-m}^{*}(\tau), \tau^{\prime}\right), \\
& x_{m}^{*}\left(\tau^{\prime}\right) \preceq B_{m}\left(x_{-m}^{*}(\tau), \tau^{\prime}\right) .
\end{aligned}
$$

Proof. See Monaco and Sabarwal 2015] for sufficient conditions that guarantee the existence of an equilibrium. By Assumption (Ao5) $x_{n}^{*}(\tau)=B_{n}\left(x_{-n}^{*}(\tau), \tau\right) \preceq B_{n}\left(x_{-n}^{*}(\tau), \tau^{\prime}\right)$. Moreover, for $m=1, \ldots J B_{m}\left(x_{-m}, \tau\right)$, is decreasing in $x_{-m}$ and, due to Theorem 5 of Monaco and Sabarwal 2015], all players' actions increase after the shock: $x_{n}^{*}(\tau) \preceq x_{n}^{*}\left(\tau^{\prime}\right)$, we then have

$$
x_{m}^{*}\left(\tau^{\prime}\right)=B_{m}\left(x_{-m}^{*}\left(\tau^{\prime}\right), \tau^{\prime}\right) \preceq B_{m}\left(x_{-m}^{*}(\tau), \tau^{\prime}\right)
$$

This proves the claim that the long-run best reply is smaller than the short-run best reply, that is, the LeChatelier principle is violated.

The short-run reply of each player to the shock, $\tau^{\prime}>\tau$, is to increase its strategy, due to the single-crossing property, Assumption (Ao5). Moreover, under the assumptions of our Proposition 3. Monaco and Sabarwal 2015] (Theorem 5) show that all players' equilibrium strategies increase after the shock. But then for each player, say $m$, who considers rivals' strategies as strategic substitutes, the higher strategies of the other players imply that the long-run best reply of Player $m$ is smaller than its short-run best reply, violating the LeChatelier principle.

Intuitively, each player's long-run response incorporates the direct effect of the shock, as well as the indirect effect arising from the reaction to the other players' strategy adjustments. As long as the overall best-reply function increases for the players with strategic substitutes, then that automatically results in players with strategic complements having both direct and indirect effects positive. That in turn results in at least one equilibrium such that every player's strategy is higher, due to results by Monaco and Sabarwal 2015. However, for the players with strategic substitutes, 
higher strategies by others imply that the indirect effect is negative while the direct effect is positive due to the single-crossing property, resulting in the principle failing to hold and long-run response being lower than the short-run response. In Section 4 we characterize necessary and sufficient conditions under which the LeChatelier principle holds for covariant shocks in two-player games of strategic substitutes with differentiable payoff functions.

Milgrom and Roberts 1996 show that LeChatelier principle applies to non-strategic environments where decisions are taken by one firm while analyzing idiosyncratic shocks and assuming that the firm's payoff function is supermodular in all decision variables (when there are more than two decision variables). The breakdown of the principle for a covariant shock in the games of strategic substitutes highlights why the principle might fail to hold for covariant shocks in non-strategic environments when decisions are submodular, that is, an increase in one decision variable decreases the marginal return from increasing the other decision variable.

Consider the original example of the LeChatelier principle: a price-taking firm that chooses labor and capital according to the wage and the interest rate in the market. Suppose that the wage has increased and the firm can adjust only labor in the short run. The firm then lowers the amount of labor employed in the short run. If labor and capital are submodular, in the long run the decreased labor implies that the firm should increase capital, and that in turn leads to an even larger decrease in labor: the original formulation of the principle in economics. Instead, suppose that the exogenous shock increased the interest rate at the same time as it increased the wage (covariant shock), for example, a higher inflation might increase interest rates and wages at the same time. In this case, the direct effect of an increased interest rate could lead to an overall capital decrease, despite the incentive to increase capital due to the initial labor decrease, and so lead to an increase in labor, counteracting the short-run labor reduction and so the principle fails to hold.

\section{$3.2 \quad$ Idiosyncratic shocks}

For the rest of the Section we focus on idiosyncratic shocks. While the LeChatelier principle sometimes fails here too, we can say more about the effects of idiosyncratic shocks than about the effects of covariant shocks. As above let player $n$ 's payoff function depend on its own strategies, competitors' strategies, and a parameter: $f_{n}\left(x_{n}, x_{-n}, \tau\right)$.

The game $\Gamma=\left\{N,\left(S_{n}, f_{n}, n \in N\right)\right\}$ is a submodular game of N-players under Assumptions (A1)(A4) after we replace increasing differences in (A4) by decreasing differences. This implies that in submodular games within player strategies are supermodular, but different players' strategies are submodular (strategic substitutes).

Given that a submodular N-player game is a cardinally supermodular (in the sense of Milgrom and Roberts 1990]) if and only if $\mathrm{N}=2$ (See Vives 1990 for homogeneous products and Hoernig [2003] for differentiated products), we thereby extend the LeChatelier principle to these environments for idiosyncratic shocks:

Corollary 1 Consider 2-player submodular games, that is, Assumptions (A1), (A2), (A3) are 
satisfied and $f_{i}$ has decreasing differences in $x_{i}$ and $x_{j}$. If Assumption (A5) also holds, for an idiosyncratic shock increasing $\tau$ to $\tau^{\prime}$ the results of Proposition 1 apply.

Intuitively, in a 2-player submodular game if we take, say, Player 2's strategy vector being $-x_{2}$ instead of $x_{2}$ the assumption of decreasing differences in $\left(x_{1}, x_{2}\right)$ is equivalent to assuming increasing differences in $\left(x_{1},-x_{2}\right)$ and thereby the game becomes a supermodular game. The same intuition allows Milgrom and Roberts [1996] to arrive at their Theorem 2, where it does not matter whether the production function is supermodular or submodular in capital and labor. The functional form used, $f(x, y ; r, w)=p g(x, y)-r y-w x$, ensures that a change in the interest rate $r$ is an idiosyncratic shock to capital decision $y$ and a change in the wage $w$ is an idiosyncratic shock to labor decision $x$. And there are only two decisions: capital and labor, akin to the requirement in the Corollary that $N=2$.

It is instructive to see why $N=2$ is required. Let's analyze a game that is, in a sense, a differentiated product Cournot. Suppose that there are three firms in the market. Further suppose that the price that the first firm receives depends only on the sum of the quantities of first and second firms, $P_{1}\left(q_{1}+q_{2}\right)$, the price that the second firm receives depends only on the sum of the quantities of the second and the third firms, $P_{2}\left(q_{2}+q_{3}\right)$, and the price that the third firm receives depends only on the sum of the quantities of the third and the first firms, $P_{3}\left(q_{3}+q_{1}\right)$. In other words, from the perspective of Firm 1 , only $q_{2}$ is its strategic substitute, from the perspective of Firm 2, only $q_{3}$ is its strategic substitute, and from the perspective of Firm 3, only $q_{1}$ is its strategic substitute: effectively a Cournot version of Salop's circular city, except that the circular city is a one-way road or a Condorcet-type setup to use an example from political theory. Suppose that Firm 1's cost increases. This leads to a short-run response of decreasing its quantity produced, $q_{1}$. However, in the long run, Firm 3 produces more due to Firm 1's short-run quantity decrease, Firm 2 produces less due to Firm 3's quantity increase, and therefore there is an incentive for Firm 1 to increase its production due to Firm 2's production decrease, negating the LeChatelier principle. The pattern is only this stark for illustration purposes. This result still holds if, for example, $P_{1}$ is also a function of $q_{3}$, as long as the effect of $q_{3}$ is, in a Monaco and Sabarwal [2015] sense, smaller in magnitude.

We need conditions to ensure that this type of a cycle does not occur. Lady and Quirk 2010] consider Morishima conditions, due to Morishima [1952]. Adopting these conditions to the context in the paper results in the following definition.

Definition 7 (Morishima Conditions) A game satisfies Morishima conditions

(AM1) if decision $i$ is a strategic complement (substitute) to decision $j$, then decision $j$ is a strategic complement (substitute) to decision $i$;

(AM2) if decision $i$ is a strategic complement to decision $j$, and decision $j$ is a strategic complement to decision $k$, then decision $i$ is a strategic complement to decision $k$;

(AM3) if decision $i$ is a strategic substitute to decision $j$, and decision $j$ is a strategic substitute to decision $k$, then decision $i$ is a strategic complement to decision $k$; 
(AM4) if decision $i$ is strategic complement (substitute) to decision $k$, and decision $j$ is a strategic complement (substitute) to decision $k$, then decision $i$ is a strategic complement to decision $k 19$

Effectively, these conditions ensure no cycles as described above. Condition (AM1) ensures either supermodular or submodular games: a game of strategic heterogeneity fails Morishima conditions. The difference between $N=2$ and $N>2$ becomes clear in this context. If the game has only two strategic decisions, then it does not matter whether the decisions are supermodular or submodular, the Morishima conditions are satisfied in either case. Of course this also holds in non-strategic environments, getting us back to the submodular example for $N=2$ in Milgrom and Roberts 1996.

Proposition 4 Under Assumptions (Ao1), (Ao2), (Ao5), suppose that the game, $\Gamma$, satisfies Morishima conditions. Consider a shock increasing $\tau$ to $\tau^{\prime}$ and affecting directly only Player $n$ 's decision $i$ (idiosyncratic shock). Then the result of Proposition 1 holds for Player $n$ :

$$
\overline{X_{n}^{*}}(\tau) \preceq \overline{B_{n}}\left(\overline{X_{-n}^{*}}(\tau), \tau^{\prime}\right) \preceq \overline{X_{n}^{*}}\left(\tau^{\prime}\right)
$$

The same is true for the smallest pure Nash equilibrium and the smallest best response function:

$$
\underline{X_{n}^{*}}(\tau) \preceq \underline{B_{n}}\left(\overline{X_{-n}^{*}}(\tau), \tau^{\prime}\right) \preceq \underline{X_{n}^{*}}\left(\tau^{\prime}\right)
$$

Proof. The first inequality is due to the single-crossing property (Ao5). Morishima conditions ensure that any feedback effects from player $n$ 's other actions and from other players' reactions are all positive and thus increase player $n$ 's best response, that is, the second inequality.

Moreover, the results in Lady and Quirk [2010] show that unless a game is supermodular or satisfies Morishima conditions, we have to impose conditions that balance direct response to the shock with indirect response arising from reactions to other players' strategy adjustments, as in Proposition 3 .

We borrow the results of the literature on submodular games to generalize further conditions under which the principle holds. Novshek 1985 shows that any N-player submodular game is cardinally supermodular (in the sense of Milgrom and Roberts [1990]) if each player's payoff is (differentiably) submodular in own strategy and the sum of the rivals' strategies. His finding brings us

Corollary 2 Assume (A1), (A2), (A3), (A5) and that each player's payoff, $f_{i}$, is (differentiably) submodular in own strategy, $x_{i}$, and in the sum of the rivals' strategies, $\sum_{j \neq n} x_{j}$. For an idiosyncratic shock increasing $\tau$ to $\tau^{\prime}$ the results of Proposition 1 apply.

\footnotetext{
${ }^{10}$ Lady and Quirk 2010] consider the LeChatelier principle in the context of a market system of price-taking firms, similar to Samuelson [1960]. Accordingly, their setup is somewhat different: in particular, prices of products that are complements are effectively submodular and prices of substitutes are supermodular.
} 
A quintessential example of this setup is a N-player homogeneous product Cournot game where the firms' costs are linear. Let $X_{-n} \equiv \sum_{j \neq n} x_{j}$ be the sum of Player n's competitors' strategies and $B_{n}\left(X_{-n}, \tau\right)$ be Player n's best-reply function. For submodular games, we assume that $B_{n}$ is non-increasing in $X_{-n}$, which is a common assumption in the literature on Cournot games, see Hahn [1962], Novshek [1985], and Amir and Lambson 2000]. We also assume that the rest of the industry's cumulative best reply is decreasing in Player n's choice: $B_{-n}\left(X_{n}\right)$ is decreasing in $X_{n}$. Dixit [1986] shows that this condition holds in homogeneous Cournot oligopoly, as long as each Player's best reply function is decreasing, which we already assumed.

Proposition 5 Assume (A1), (A2), (A3), and that Player n's best-reply, $B_{n}\left(X_{-n}, \tau\right)$ is weakly decreasing in the sum of the other players' strategies, $X_{-n}=\sum_{j \neq n} x_{j}$, is weakly increasing in $\tau$, and the sum of the other players' best replies, $B_{-n}\left(X_{n}\right)$ is weakly decreasing in $X_{n}$. Then the result of Proposition 1 applies.

Proof. For equilibrium existence see, for example, Vives 2001. Since $\overline{B_{n}}$ is weakly increasing in $\tau, \overline{B_{n}}\left(X_{-n}, \tau\right) \preceq \overline{B_{n}}\left(X_{-n}, \tau^{\prime}\right)$. Since $\overline{B_{-n}}\left(X_{n}\right)$ is weakly decreasing in $X_{n}, \overline{B_{-n}}\left(\overline{B_{n}}\left(X_{-n}, \tau^{\prime}\right)\right) \preceq$ $\overline{B_{-n}}\left(\overline{B_{n}}\left(X_{-n}, \tau\right)\right)$. Finally, since $\overline{B_{n}}$ is non-increasing in the rest of the industry's reply,

$$
\overline{X_{n}}\left(\tau^{\prime}\right)=\overline{B_{n}}\left(\overline{X_{-n}}\left(\tau^{\prime}\right), \tau^{\prime}\right) \succeq \overline{B_{n}}\left(\overline{X_{-n}}(\tau), \tau^{\prime}\right) \succeq \overline{B_{n}}\left(\overline{X_{-n}}(\tau), \tau\right)=\overline{X_{n}}(\tau) .
$$

Further cycles of adjustments are possible until the equilibrium is reached, but each one simply increases the feedback loop effect. The proof follows symmetric arguments for the smallest Nash equilibrium.

Relatedly, Koebel and Laisney 2014 derive conditions under which the LeChatelier principle will hold at least on aggregate (combining all the firms in the industry) in homogeneous Cournot oligopoly games. In their model, shocks are changes in input prices.

Amir 1996] illustrates more general conditions under which a Cournot game is ordinally supermodular (in the sense of Milgrom and Shannon [1994]), so that the results of our Proposition 2 apply. Using his findings we further extend the applicability of the principle in Cournot settings:

Corollary 3 The following Cournot games are ordinally supermodular

- Cournot duopoly with log-concave decreasing demand function and arbitrary (increasing) cost functions,

- Symmetric oligopoly with linear production costs, bounded production capacities and log-convex net-of-cost demand function (with the original order on output spaces),

and so in these Cournot games under our Assumption (Ao5), for an idiosyncratic shock increasing $\tau$ to $\tau^{\prime}$ the results of Proposition 2 apply. 


\section{A Model of Two Decisions}

One of the main points of this paper is that LeChatelier principle applies to strategic decisions in the same way as it does to non-strategic decisions, and fails in the same types of situations in both strategic and non-strategic contexts. Thus, for the principle to hold, it does not matter whether a market has a monopolist or independent firms making these decisions. What matters is whether the decision variables are supermodular or submodular, and if they are submodular, then whether the shock to the parameter is idiosyncratic (affecting only one decision variable) or covariant (affecting more than one decision variable).

To highlight this and to nest our applications into the same framework, we model a market where two decisions are made. These decisions could be the prices that a two-product firm sets for its products or prices (or quantities) that two competing single-product firms choose for their products or price and quality that a single-product firm chooses for its product. The model below nests these and other possibilities, including partial ownership of one firm by another. We describe the different settings in the following section.

\subsection{First-Order Condition Approach}

In the previous sections we use monotone comparative statics analysis and lattice theory to highlight the generality of conditions under which the principle applies in strategic environments (games). Here we provide a complementary analysis of a model with two decisions using standard first-order condition techniques to shed some light on the mechanism at play.

We denote the two decision variables (or strategies) in the market by $x_{i}$ and $x_{j}$ and a parameter by $t$. We assume that the strategies and the parameter are real numbers. Furthermore, we assume that $x_{i}$ is chosen to maximize decision maker (or Decider) i's objective $W_{i}$ and $x_{j}$ is chosen to maximize Decider j's objective $W_{j}$.

We make the following assumptions:

(a1) Objective functions, $W_{i}, W_{j}$, are twice continuously differentiable functions of $x_{i}, x_{j}$, and $t$.

(a2) There exists a unique and stationary solution to the optimization problems ${ }^{20}$

$$
\begin{array}{r}
S O C_{i} \equiv \partial_{x_{i}}^{2} W_{i}<0, S O C_{j} \equiv \partial_{x_{j}}^{2} W_{j}<0 \\
\left|\partial_{x_{i}}^{2} W_{i}\right| \geq\left|\partial_{x_{i} x_{j}}^{2} W_{i}\right|,\left|\partial_{x_{j}}^{2} W_{j}\right| \geq\left|\partial_{x_{i} x_{j}}^{2} W_{j}\right|
\end{array}
$$

(a3) Optimal strategies are either non-decreasing in $t, \partial_{x_{i} t}^{2} W_{i} \geq 0, \partial_{x_{j} t}^{2} W_{j} \geq 0$, or non-increasing in $t, \partial_{x_{i} t}^{2} W_{i} \leq 0, \partial_{x_{j} t}^{2} W_{j} \leq 0$.

We make the following definitions:

\footnotetext{
${ }^{20}$ We denote partial derivatives as $\partial_{x_{i}} W_{i} \equiv \frac{\partial W_{i}}{\partial x_{i}}, \partial_{x_{i}}^{2} W_{i} \equiv \frac{\partial^{2} W_{i}}{\partial x_{i}^{2}}, \partial_{x_{i} x_{j}}^{2} W_{i} \equiv \frac{\partial^{2} W_{i}}{\partial x_{i} \partial x_{j}}$.
} 
Definition 8 (supermodular decisions (strategic complements in games)) The two decisions are supermodular if the marginal profit from increasing one strategy strictly increases in the other: $\partial_{x_{i} x_{j}}^{2} W_{i}>0, \partial_{x_{i} x_{j}}^{2} W_{j}>0$.

Definition 9 (submodular decisions (strategic substitutes in games)) The two decisions submodular if the marginal profit from increasing one strategy strictly decreases in the other: $\partial_{x_{i} x_{j}}^{2} W_{i}<$ $0, \partial_{x_{i} x_{j}}^{2} W_{j}<0$.

Definition 10 (independent decisions) The two decisions are independent if the marginal profit from increasing one strategy does not depend on the other: $\partial_{x_{i} x_{j}}^{2} W_{i}=0, \partial_{x_{i} x_{j}}^{2} W_{j}=0$.

Definition 11 (increasing vs decreasing differences in the parameter) If the marginal profitability of one strategy, say $x_{i}$, increases in the parameter, $\partial_{x_{i} t}^{2} W_{i}>0$, we say that $W_{i}$ has increasing differences in $x_{i}$ and $t$. Symmetrically, if $x_{i}$ 's marginal profitability decreases in the parameter, $\partial_{x_{i} t}^{2} W_{i}<0$, we say that $W_{i}$ has decreasing differences in $x_{i}$ and $t$.

Under our assumptions (a1) and (a2) there exists an interior solution to the above maximization problems where the first-order conditions must hold: $\partial_{x_{i}} W_{i}=0$ and $\partial_{x_{j}} W_{j}=0$.

We define the feedback effect from strategy $x_{j}$ to strategy $x_{i}$, as

$$
F B_{i} \equiv \partial_{x_{i} x_{j}}^{2} W_{i}
$$

and symmetrically define the feedback effect from strategy $x_{i}$ to strategy $x_{j}$, as $F B_{j} \equiv \partial_{x_{i} x_{j}}^{2} W_{j}$.

\subsection{Pass-through of exogenous shocks}

Consider a binding regulation on $x_{j}$, such as a price ceiling if $x_{j}$ is price of product $\mathrm{j}$. In this case, $\frac{d x_{i}}{d x_{j}} \cdot \Delta x_{j}$ measures the change in $x_{i}$ induced by the regulation where $\Delta x_{j}$ is the change in $x_{j}$ due to the regulation- the effect on one endogenous variable, $x_{i}$, of an exogenous restriction on the other endogenous variable, $x_{j}$. To analyze this effect we totally differentiate the first-order condition of Product $i, \partial_{x_{i}} W_{i}=0$, with respect to Product $j$ 's variable $\left(x_{j}\right)$ :

$$
-S O C_{i} \frac{d x_{i}}{d x_{j}}=\partial_{x_{i} x_{j}}^{2} W_{i}=F B_{i}
$$

The pass-through of this shock is determined by whether the decisions are supermodular from Decider i's perspective, that is, whether $\partial_{x_{i} x_{j}}^{2} W_{i}>0$.

Proposition 6 Consider a binding exogenous restriction that lowers $x_{j}$, for example, a binding price cap. This restriction decreases (increases) the optimal level of the other variable, $x_{i}$, if the decision variables are supermodular or $F B_{i}>0$ (submodular or $\left.F B_{j}<0\right)$.

Proof. If the decision variables are supermodular, we have $\partial_{x_{i} x_{j}}^{2} W_{i}>0$. Hence, the right hand-side of equality 5 is positive. Given that $-S O C_{i}$ is positive by Assumption (a2) we prove that $\frac{d x_{i}}{d x_{j}}>0$ 
if the decision variables are supermodular or $F B_{i}>0$. The proof is symmetric if the decision variables are submodular or $F B_{i}<0$.

We now proceed to analyze the effect of an exogenous shock to the parameter, $t$, on the optimal levels of the endogenous variables, $x_{i}, x_{j}$. We derive the effect of the parameter on the endogenous variables by totally differentiating the optimality conditions for these variables, $\partial_{x_{i}} W_{i}=0$ and $\partial_{x_{j}} W_{j}=0$ :

$$
\begin{aligned}
& -S O C_{i} \frac{d x_{i}}{d t}=\partial_{x_{i} t}^{2} W_{i}+F B_{i} \frac{d x_{j}}{d t} \\
& -S O C_{j} \frac{d x_{j}}{d t}=\partial_{x_{j} t}^{2} W_{j}+F B_{j} \frac{d x_{i}}{d t} .
\end{aligned}
$$

Consider the first equation above. The effect of a change in $t$ can be decomposed into a direct effect of this shock on Decider $i$ 's welfare, $\partial_{x_{i} t}^{2} W_{i}$, and an indirect effect of the shock changing Decider $j$ 's optimal decision, $x_{j}$, which in turn feeds back into the optimal decision on $x_{i}, F B_{i} \frac{d x_{j}}{d t}$. We define the short-run adjustment of Decider $i$ to the shock as the direct effect of the shock where only the directly affected variable, $x_{i}$, is adjusted, that is, setting $\frac{d x_{j}}{d t}=0$. We define the long-run adjustment of Decider $i$ to the shock as the sum of the direct and indirect effects after both variables are adjusted. We say that the LeChatelier principle holds if the long-run adjustment of the directly affected variable is greater than the short-run adjustment.

The difference between the effects of covariant and idiosyncratic shocks becomes clearer. An idiosyncratic shock on one variable, say $x_{i}$, is a shock for which the direct effect on the other variable is zero, $\partial_{x_{j} t}^{2} W_{j}=0$. In other words, the only effect of an idiosyncratic shock on the other variable is the indirect effect, $F B_{j} \frac{d x_{i}}{d t}$, that is the feedback of the directly affected variable.

We can express the long-run pass-through of the shock onto decision variable $x_{i}, \frac{d x_{i}}{d t}{ }^{L R}$, explicitly by solving the system of equations, 6a and (6b), to arrive at:

$$
{\frac{d x_{i}}{d t}}^{L R}=\frac{\partial_{x_{i} t}^{2} W_{i}+F B_{i} \frac{\partial_{x_{j} t}^{2} W_{j}}{-S O C_{j}}}{-S O C_{i}-\frac{F B_{i} F B_{j}}{-S O C_{j}}} .
$$

The numerator of the long-run pass-through is the sum of two terms: the direct effect of the change in $t$ on Decision $\mathrm{i}$ and the feedback of the direct effect on Decision $\mathrm{j}$ (with the sign of the effect depending on whether the decisions are submodular or supermodular from the perspective of Decider i).

The short-run pass-through of the shock onto $x_{i}$ is then (by setting feedback effects at zero)

$$
{\frac{d x_{i}}{d t}}^{S R}=\frac{\partial_{x_{i} t}^{2} W_{i}}{-S O C_{i}}
$$

The LeChatelier principle holds if $\left|\frac{d x_{i}}{d t} S R\right|<\left|\frac{d x_{i}}{d t}{ }^{L R}\right|$. The first difference between the long-run and the short-run pass-throughs is the second term in the denominator of $[7],-\frac{F B_{i} F B_{j}}{-S O C_{j}}$. It is the "feedback loop effect": the effect of a change in $x_{i}$ affecting $x_{j}$ that in turn affects $x_{i}$. If the two 
decisions are symmetrically submodular or supermodular, the feedback effects, $F B_{i}, F B_{j}$, are of the same sign: $\operatorname{sign}\left(\partial_{x_{i} x_{j}}^{2} W_{i}\right)=\operatorname{sign}\left(\partial_{x_{i} x_{j}}^{2} W_{j}\right)$. In these cases the feedback loop effect increases the shock pass-through in the long run. Feedback effects might be of different signs, for example, if decision $i$ was a submodular for decision $j$, while decision $j$ was supermodular for decision $i$, like in the games of strategic heterogeneity we discussed in Section 3 , see also Monaco and Sabarwal 2015 .

The second difference between the long-run and short-run pass-throughs is the second term in the numerator of (7), $F B_{i} \frac{\partial_{x_{j}}^{2} W_{j}}{-S O C_{j}}$, that we refer to as the "numerator effect." The shock directly affects the optimal $x_{j}$, and that effect feeds back into the optimal long-run choice of $x_{i}$. By definition the numerator effect is zero for an idiosyncratic shock on $t$ affecting only $x_{i}$ since then $\partial_{x_{j} t}^{2} W_{j}=0$. Therefore, the sign of feedback loop effect determines whether the principle holds (reflecting Theorem 2 of Milgrom and Roberts 1996]):

Corollary 4 Consider an idiosyncratic shock on $t$ that directly affects only $x_{i}$, the short-run adjustment of $x_{i}$ to the shock, when only $x_{i}$ adjusts, is smaller than the long-run adjustment of $x_{i}$, when $x_{j}$ also adjusts, that is, the LeChatelier principle holds if both decisions are symmetrically submodular or supermodular.

If there is a covariant shock that affects directly both players, the LeChatelier principle might fail to hold even for two players, as we discuss in Section 3. The reason becomes clearer here: for a covariant shock $\partial_{x_{i} t}^{2} W_{i} \neq 0, \partial_{x_{j} t}^{2} W_{j} \neq 0$, the feedback loop effect might be counteracted by the numerator effect, requiring further conditions on when the principle is satisfied. Moreover, as we showed in the previous Section, the principle does not need to hold for idiosyncratic shocks with more than two players.

Proposition 7 Consider a covariant shock on $t$ (affecting both variables directly) and suppose that the decision variables have increasing differences in $t, \partial_{x_{i} t}^{2} W_{i}>0, \partial_{x_{j} t}^{2} W_{j}>0$, and the two decisions are supermodular, $F B_{i}, F B_{j}>0$, then the short-run adjustment of a given variable to the shock, when only that variable adjusts, is smaller than the long-run adjustment of that variable, when the other variable also adjusts, that is, the LeChatelier principle holds.

\section{Proof.}

When the decisions have increasing differences in $t$, the direct effect on decision $i$ is positive, $\partial_{x_{i} t}^{2} W_{i}>0$, and also the fraction multiplying the feedback effect in the numerator of $\frac{d x_{i}}{d t}{ }^{L R}$, equation (7), is positive. In this case, if the decisions are supermodular, then the feedback effects are also positive. Hence, the feedback effect from Product $j$ to Product $i$ ("numerator effect") increases the numerator and thereby increases the pass-through of the shock onto $x_{i}$ (given that $-S O C_{i}>0$ by Assumption (a2)). Moreover, the denominator of the long-run pass-through includes a feedback loop: any change in $x_{i}$ affects $x_{j}$, which in turns affects $x_{i}$, and so on, and the feedback loop increases the long-run pass-through compared to the short-run pass-through since the decisions are supermodular. 
The principle might be violated for covariant shocks, for instance, when the decision variables are submodular and at the same time have increasing differences in $t$ or when the decision variables are supermodular and have decreasing differences in $t$, that is, the marginal profitability of each decision decreases in the parameter. In these situations, the numerator effect can outweigh the feedback loop effect, invalidating the principle in these cases, regardless of the fact that the two decisions are made by independent players or by the same firm ${ }^{21}$

Proposition 8 Suppose that the decision variables have increasing differences in $t$ and the two decisions are submodular, then the short-run adjustment of a given variable to a covariant shock on $t$, when only that variable adjusts, is smaller than the long-run adjustment of that variable, when the other variable also adjusts, that is, the LeChatelier principle holds if and only if

$$
\partial_{x_{j} t}^{2} W_{j}<\partial_{x_{i} t}^{2} W_{i} \frac{-F B_{j}}{-S O C_{i}}
$$

Proof. Recall that $\partial_{x_{i} t}^{2} W_{i}$ is the direct effect of the shock on Decider $i$ 's welfare, $\partial_{x_{j} t}^{2} W_{j}$ is the direct effect on Decider $j$ 's welfare, and the short-run pass-through of $t$ onto $x_{i}$ (equation (8)) is

$$
{\frac{d x_{i}}{d t}}^{S R}=\frac{\partial_{x_{i} t}^{2} W_{i}}{-S O C_{i}}
$$

When the decisions have increasing differences in $t$, both direct effects are positive. This implies that the short-run pass-through of $t$ onto $x_{i}$ is positive given that $-S O C_{i}>0$ by Assumption (a2). The long-run pass-through of $t$ onto $x_{i}$ (equation (7)) is

$$
{\frac{d x_{i}}{d t}}^{L R}=\frac{\partial_{x_{i} t}^{2} W_{i}\left(-S O C_{j}\right)+\left(F B_{i}\right) \partial_{x_{j} t}^{2} W_{j}}{S O C_{i} S O C_{j}-F B_{i} F B_{j}}
$$

Positive direct effects and Assumption (a2) together imply that the long-run pass-through of $t$ onto $x_{i}$ is also positive. Moreover, we have negative feedback effects, $F B_{i}<0, F B_{j}<0$, since the decisions are submodular. Comparing the long-run pass-through with the short-run pass-through, it is straightforward to show that ${\frac{d x_{i}}{d t}}^{L R}>{\frac{d x_{i}}{d t}}^{S R}$ if and only if Condition $(9)$ holds.

In order to ensure the principle for $x_{i}$ Condition (9) requires that the indirect effects on the other strategy, $x_{j}$, (the effects that are adjusted in the long run) are not outweighed by the direct effects on $x_{j}$. Intuitively, given that the strategies have increasing differences in $t$ the shock's direct effect on both strategies is positive. Since the strategies are submodular, the indirect effects on one variable go opposite direction to the direct effects on that variable. If the direct effects on $x_{j}$ are outweighed by the indirect effects on $x_{j}$, then the shock should decrease $x_{j}$ and the feedback from the adjustment of $x_{j}$ on $x_{i}$ is positive, the same as the direct effect on $x_{i}$.

Condition (9) holds exactly when the sufficient condition derived by Roy and Sabarwal [2010] for their Theorem 1 to hold in $\mathbb{R}^{N}$ is not satisfied (see derivations between their Corollary 1 and

\footnotetext{
${ }^{21}$ To complete the comparison with the standard presentation of the principle, the term $\partial_{x_{i} t}^{2} W_{i}$ in the numerator is often normalized to 1 in the literature, see for example Lady and Quirk 2010.
} 
Corollary 2). It is intuitive that our condition requires the opposite of Roy and Sabarwal [2010], since they are interested in when direct effects outweigh the indirect effects of a parameter change in a submodular game to sign the net effect of the shock on the equilibrium strategies 22

There is a similar condition in Monaco and Sabarwal [2015]. A simple modification to our condition (9) allows for general feedback effects, such as in games of strategic heterogeneity.

\section{Applications}

\subsection{Possible structural assumptions on the welfare functions}

More structure on the welfare functions in Section 4 might be helpful in some contexts. Suppose that

$$
\begin{aligned}
& W_{i}=\pi_{i}\left(x_{i}, \gamma x_{j}, t\right)+\beta_{i} \pi_{j}\left(x_{j}, x_{i}, \theta t\right), \\
& W_{j}=\beta_{j} \pi_{i}\left(x_{i}, \gamma x_{j}, t\right)+\pi_{j}\left(x_{j}, x_{i}, \theta t\right),
\end{aligned}
$$

where $\pi_{i}\left(x_{i}, \gamma x_{j}, t\right)$ refers to the profit from strategy $x_{i}$ when the other decision variable is at level $x_{j}$ and parameter is at level $t, \pi_{j}\left(x_{j}, x_{i}, \theta t\right)$ refers to the profit from strategy $x_{j}$ when the other decision variable is at level $x_{i}$ and parameter is at level $t$. Parameter $\beta_{i} \in[0,1]$ measures how much Decider $i$ cares about the profit from strategy $x_{j}$, similarly, $\beta_{j} \in[0,1]$ measures how much Decider $j$ cares about the profit from strategy $x_{i}$. Parameter $\gamma \in[0,1]$, measures how much decision variable $x_{j}$ affects the profit from strategy $x_{i}$, and $\theta \in[0, \bar{\theta}]$ measures how much an exogenous shock on parameter $t$ affects the profit from strategy $x_{j}$ (where we normalize the effect of the shock on the profit from strategy $x_{j}$ ). To contextualize the model, imagine two single-product firms, $i$ and $j$. Firm $i$ derives a profit of $\pi_{i}$ from its Product $i$ based on the choices of two strategies, $x_{i}$ chosen by Firm $i$ and $x_{j}$ chosen by Firm $j$ (for example, prices or quantities), and based on the exogenous variable $t$ (for example, taxes or marginal costs). Each firm might also own a part of the other firm's main business $\left(\beta_{i}, \beta_{j}>0\right)$, without exercising control.

Setting $\beta_{i}=\beta_{j}=0$ results in the standard duopoly setup. Setting $\beta_{i}=\beta_{j}=1$ means that the firms' incentives are perfectly aligned: in other words, this is equivalent to a two-product firm. The intermediate values correspond to partial ownership without control as in, for example, O'Brien and Salop 2000, see also Azar, Schmalz, and Tecu 2014 for an empirical application.

\footnotetext{
${ }^{22}$ In submodular games with more than two players Roy and Sabarwal 2010 requires the following condition to sign the net effect of the shock on the equilibrium strategies (using our notation):

$$
\partial_{x_{j} t}^{2} W_{j}+\sum_{k \neq j} \partial_{x_{k} x_{j}}^{2} W_{j} \frac{\partial_{x_{k} t}^{2} W_{k}}{-\partial_{x_{k}}^{2} W_{k}}>0
$$

Their condition suggests a way to generalize our condition 9 to more than two decisions: for the principle to apply for Player $i$, a similar condition to 9 has to apply for each Player $j \neq i$ while summing up indirect effects across all rivals of Player $j$, that is, the opposite of $\sqrt{10}$ should hold for each Player $j \neq i$. Intuitively, if for each rival of Player $i$, direct effects are outweighed by its indirect effects, then the feedback from the rivals' on Player $i$ has to be the same as the direct effect on Player $i$.
} 
Table 1: Some of the special cases nested into the model.

\begin{tabular}{|l|c|}
\hline Special case & Parameter values \\
\hline \hline Single-product monopoly $i$ & $\gamma=0$ and $\beta_{i}=0$ \\
\hline Single-product duopoly & $\beta_{i}=\beta_{j}=0$ \\
\hline Two-product monopoly & $\beta_{i}=\beta_{j}=1$ \\
\hline Two-product monopoly and one-sided effects & $\beta_{i}=\beta_{j}=1$ and $\gamma=0$ \\
\hline Two-period monopoly (full commitment) & $\beta_{i}=\delta$ (discount rate) and $\beta_{j}=1 / \delta$ and $\gamma=0$ \\
\hline $\begin{array}{l}\text { Two-period monopoly (no commitment to pe- } \\
\text { riod 2 decision, } x_{j} \text { ) }\end{array}$ & $\beta_{i}=\delta$ (discount rate) and $\beta_{j}=0$ and $\gamma=0$ \\
\hline Idiosyncratic shock to parameter $t$ & $\theta=0$ \\
\hline
\end{tabular}

Setting parameter $\gamma=0$ accounts for the possibility that strategy $x_{j}$ has no direct effect on the profit from strategy $x_{i}$. For example, Product $j$ could be an add-on that is not salient to consumers (like in Gabaix and Laibson 2006]) or whose price (or characteristics) consumers are not aware of when they choose their base product (Product $i$ ) (like in Ellison 2005]). The profit derived from Product $i$ is then independent of price or characteristics of Product $j$. The same firm often owns both a base product and its add-on, and that can be captured by setting $\beta_{i}=\beta_{j}=1$. In this case, while there is no direct effect of $x_{j}$ on the profit derived from Product $i$, the firm still accounts for $x_{j}$ while setting $x_{i}$ since the firm internalizes the profit derived from Product $\mathrm{j}$. We refer to this scenario as one-sided effects case.

Setting parameter $\gamma=0$ and parameters $\beta_{i}=\delta$ and $\beta_{j}=1 / \delta$ corresponds to a two-period model of a monopolist, which chooses $x_{i}$ and $x_{j}$ in period 1, gets a profit of $\pi_{i}$ in period 1 , a profit of $\pi_{j}$ in period 2 while discounting the second period profits by $\delta$. If the firm cannot commit in the first period to its second-period decision, $x_{j}$, then $\beta_{j}=0$. This application highlights the point that covariant shocks might be affecting the same firm's production function overtime. As mentioned throughout the text, the principle might fail, see Castillo 2015 for more on the principle in intertemporal setting.

Finally, parameter $\theta$ allows us to differentiate between a covariant shock (a tax or cost shock affecting both decision variables directly, for example, a market-wide tax change or an input price change in the case of duopoly) and an idiosyncratic shock (a tax or cost shock affecting only one decision variable directly, for example, a firm specific cost shock in the case of duopoly or a product specific tax in the case of two-product monopoly with one-sided effect:23). Setting $\theta=0$ is equivalent to considering an idiosyncratic shock to parameter $t$ which affects only strategy $x_{i}$ directly 24

\footnotetext{
${ }^{23}$ Note that in general for a two-product monopolist if there is a tax / cost shock on only one product, the other product's optimal variable is also directly affected since the monopolist accounts for the profits from both products

${ }^{24} \mathrm{~A}$ more complete nested model would allow parameters $(\gamma, \theta, t)$ to vary across decisions and so have $i, j$ subscripts on all the parameters described above (not only on $\beta \mathrm{s}$ ); however, this would complicate the exposition and we do not need such complexity for our purposes, so we leave the model as it is and note that these more general features could be incorporated into the above model without any difficulty.
} 


\subsection{Two-product Monopoly}

One important application of our theory is multiproduct firms' cost pass-through. For example, a multiproduct monopolist experiences a cost shock to one of the products, adjusts that product's price in the short run and can adjust the other prices only in the long run. The firm might not adjust all prices globally in the short-run, for instance, because the division that sets the price of the directly affected product adjusts the price, but it takes time for other divisions to adjust the other products' prices or the firm might face exogenous restrictions on the prices of other products, like long-term contracts, which would not allow the firm to adjust these prices instantaneously. In this case the short-run pass-through is the direct effect of the cost shock and the long-run passthrough incorporates also the feedback effects of the other products' price adjustments in the initial product's price.

It's worth noting that shocks in the case of two-product monopoly are covariant except for special contexts. Consider a tax on product $i$. This tax directly affects product $j$ : product $i$ 's margin is lower due to the tax, thus even if price of product $i$ does not change, price of product $j$ should still be adjusted to account for the changes in the margin of product $i$ as long as product $j$ 's price affects product $i$ 's demand. Hence, in general it is not clear apriori whether LeChatelier principle applies in multiproduct monopoly context.

We assume that each demand is decreasing in its own price, $\partial_{p_{i}} D_{i}<0$, increases in the other price if the products are substitutes, $\partial_{p_{j}} D_{i}>0$, and decreases in the other price if the products are complements, $\partial_{p_{j}} D_{i}<0$. For now, the partial derivatives are commutative: $\partial_{p_{i} p_{j}}^{2} \Pi=\partial_{p_{j} p_{i}}^{2} \Pi$. To ensure existence, uniqueness and stationary of optimal prices we also assume that

$$
S O C_{i}=\partial_{p_{i}}^{2} \Pi<0,-S O C_{i} \geq\left|\partial_{p_{i} p_{j}}^{2} \Pi\right| \equiv|F B| .
$$

\subsubsection{Tax on all products}

Consider the special case of two-product monopoly that faces a cost shock, say excise tax $t$, on both products. In the two-decisions model of the previous subsection, this case corresponds to $\beta_{i}=\beta_{j}=1, \theta=1, \gamma=1$ where the endogenous variables are $x_{i}=p_{i}, x_{j}=p_{j}$. In this case, the firm's profit is

$$
\Pi=\pi_{i}\left(p_{i}, p_{j}, t\right)+\pi_{j}\left(p_{j}, p_{i}, t\right)=\left(p_{i}-t\right) D_{i}\left(p_{i}, p_{j}\right)+\left(p_{j}-t\right) D_{j}\left(p_{j}, p_{i}\right)-C\left(D_{i}\left(p_{i}, p_{j}\right), D_{j}\left(p_{j}, p_{i}\right)\right) .
$$

It is useful to first establish when prices have increasing differences with the tax. Since $\frac{\partial^{2} \Pi}{\partial p_{i} \partial t}=$ $-\partial_{p_{i}} D_{i}-\partial_{p_{i}} D_{j}, p_{i}$ has increasing differences with $t$ if and only if

$$
-\partial_{p_{i}} D_{i}>\partial_{p_{i}} D_{j}
$$

In other words, if the product are substitutes, $\partial_{p_{i}} D_{j}>0$, the effect of price $i$ on own demand has to outweigh the effect on demand of $j$. Alternatively, if the products are complements, $\partial_{p_{i}} D_{j}<0$, 
then the condition is trivially satisfied. Our result from Proposition 7 then brings us the following:

Corollary 5 Assume that $-\partial_{p_{i}} D_{i}>\partial_{p_{i}} D_{j}$. Then the short-run pass-through of the tax is smaller than the long-run pass-through if prices are supermodular.

Assuming linear cost in the case of substitute products, products' prices are likely to be supermodular. Intuitively, when the own-demand effect dominates the cross-demand effect, the direct effect of the shock on each price is positive. When one product's price increases, the demand for the substitute increases and so the indirect effect of the shock might likely be positive. For example, this is the case for linear demands. Arguably the most common context where the prices are submodular is the case of complements, since for complements increasing price of one product will lower demand for its complementary product and so lower the latter's price, i.e., the indirect effects likely to go opposite direction to the direct effects of the tax. This is the case for linear demands.

Lemma 1 Assume linear costs.

- The products' prices are supermodular if the products are substitutes and the demands have weakly increasing differences in prices, $\partial_{p_{i} p_{j}}^{2} D_{i} \geq 0, \partial_{p_{i} p_{j}}^{2} D_{j} \geq 0$.

- The products' prices are submodular if the products are complements and the demands have weakly decreasing differences in prices, $\partial_{p_{i} p_{j}}^{2} D_{i} \leq 0, \partial_{p_{i} p_{j}}^{2} D_{j} \leq 0$

Proof. Assume linear costs, $c_{i}$ and $c_{j}$, per product $i$ and $j$, respectively. The second-order cross derivative of the profit is then

$$
\partial_{p_{i} p_{j}}^{2} \Pi=\partial_{p_{j}} D_{i}+\partial_{p_{i}} D_{j}+\left(p_{i}-c_{i}-t\right) \partial_{p_{i} p_{j}}^{2} D_{i}+\left(p_{j}-c_{j}-t\right) \partial_{p_{i} p_{j}}^{2} D_{j}
$$

Given that the margins must be positive in equilibrium, it is strateigforward to see that $\partial_{p_{i} p_{j}}^{2} \Pi>0$ for substitutes, $\partial_{p_{j}} D_{i}>, \partial_{p_{i}} D_{j}>0$, as long as the second-order cross-demand effects are not too negative. Symmetrically, $\partial_{p_{i} p_{j}}^{2} \Pi<0$ for complements, $\partial_{p_{j}} D_{i}<, \partial_{p_{i}} D_{j}<0$, as long as the secondorder cross-demand effects are not too positive.

If the demands have very strong decreasing differences in prices, the indirect effects might go in the opposite direction from the direct effects and lead to submodular prices even for substitutes. Intuitively, in these cases the demand for one product decreases much more in its own price when its substitutes' price is higher, for example, this can happen if consumers' valuations for the two products are positively correlated: when one product's, say $i$ 's, price increases, consumers who stay with product $i$ are those with high willingness-to-pay for product $i$ (and high willingness-to-pay for product $j$ ) and consumers who switch to product $j$ are people with low willingness-to-pay for product $i$ and so low willingness-to-pay for product $j$, making the demand for product $j$ more sensitive to its own price. Symmetrically, for complements if the demands have sufficiently strong amount of increasing differences in prices, the indirect effects might go to the same direction as the direct effects and lead to supermodular prices. Intuitively, in these cases the demand for one 
product decreases much less in its own price when its complement's price is higher. This can happen, for example, if consumers' valuations for the two products are positively correlated (like base product and add-on model of Ellison [2005]): when one product's, say $i$ 's, price increases, consumers who stay with product $i$ are those with high willingness-to-pay for product $i$ and also high willingness-to-pay for product $j$, making the demand for product $j$ much less sensitive to price.

In the cases where the products' prices are submodular or the firm's profit has decreasing differences in each price and parameter (condition 12 is violated), Proposition 8 gives conditions under which the LeChatelier principle holds.

\subsubsection{Tax on just one product}

Consider the special case of two-product monopoly that faces a cost shock, say excise tax $t$, only on product $i$. In this case, the firm's profit is

$$
\Pi=\pi_{i}\left(p_{i}, p_{j}, t\right)+\pi_{j}\left(p_{j}, p_{i}\right)=\left(p_{i}-t\right) D_{i}\left(p_{i}, p_{j}\right)+p_{j} D_{j}\left(p_{j}, p_{i}\right)-C\left(D_{i}\left(p_{i}, p_{j}\right), D_{j}\left(p_{j}, p_{i}\right)\right) .
$$

As noted above, despite the tax falling only on one product, the shock is covariant: $\partial_{p_{j} t}^{2} \Pi=$ $-\partial_{p_{j}} D_{i} \neq 0$. However, this setting simplifies condition (12). Observe that the profit has increasing differences in $p_{i}$ and $t: \partial_{p_{i} t}^{2} \Pi=-\partial_{p_{i}} D_{i}>0$. The profit has decreasing differences in $p_{j}$ and $t$ if the products are complements: $\partial_{p_{j} t}^{2} \Pi=-\partial_{p_{j}} D_{i}>0$, so increasing $p_{j}$ becomes more profitable with the tax on its complement. On the other hand, the profit has decreasing differences in $p_{j}$ and $t$ if the products are substitutes, so increasing $p_{j}$ becomes less profitable with the tax on its substitute.

By taking the total derivate of the first-order conditions and solving them together, we derive the short-run and long-run pass-through of the tax on $p_{1}$ as (equations (7) and (8) for the case of two-product monopoly and product specific cost shock $t$ on product $i$ ):

$$
{\frac{d p_{i}}{d t}}^{S R}=\frac{\partial_{p_{i} t}^{2} \pi_{i}}{-S O C_{i}}, \frac{d p_{i}{ }^{L R}}{d t}=\frac{\partial_{p_{i} t}^{2} \pi_{i}+F B \frac{\partial_{p_{j} t}^{2} \pi_{i}}{-S O C_{j}}}{-S O C_{i}-\frac{F B^{2}}{-S O C_{j}}}
$$

Proposition 9 Consider a two-product monopoly that faces a cost shock, say excise tax $t$, only on product $i$. The short-run pass-through of the tax is smaller than the long-run pass-through: ${\frac{d p_{i}}{d t}}^{S R}<{\frac{d p_{i}}{d t}}^{L R}$, if

- the products are complements and prices are supermodular, or

- the products are substitutes and prices are submodular, or

- if $\operatorname{sign}(-F B) \frac{-\partial_{p_{i}} D_{i}}{-\partial_{p_{j}} D_{i}} \geq \operatorname{sign}(-F B) \frac{-S O C_{i}}{-F B}$.

Proof. Observe that the second term in the denominator of the long-run pass-through decreases the denominator since $F B^{2}>0$. This is the feedback loop that increases the long-run pass-through compared to the short-run pass-through, as we identified in Section 4 . When the products are 
complements, we have $\partial_{p_{j} t}^{2} \pi_{i}=-\partial_{p_{j}} D_{i}>0$. In this case if the prices are supermodular, the second term in the numerator of the long-run pass-through is also positive, hence increases the pass-through relative to the short-run pass-through. However, if the prices are submodular, it is straightforward to show that the short-run pass-through is smaller than the long-run pass-through if and only if $\frac{-\partial_{p_{i}} D_{i}}{-\partial_{p_{j}} D_{i}} \geq \frac{-S O C_{i}}{-F B}$. Symmetrically, when the products are substitutes, we have $\partial_{p_{j} t}^{2} \pi_{i}=-\partial_{p_{j}} D_{i}<0$. In this case if the prices are submodular, the second term in the numerator of the long-run passthrough is also positive, hence increases the pass-through relative to the short-run pass-through. However, if the prices are supermodular, the short-run pass-through is smaller than the long-run pass-through if and only if $\frac{-\partial_{p_{i}} D_{i}}{\partial_{p_{j}} D_{i}} \geq \frac{-S O C_{i}}{F B}$.

The first prong is a consequence of the general result with supermodular prices, the second prong is the result of a simplified structure with the tax falling on only one product, and the third prong is the application of Proposition 8. To understand the intuition suppose that the products are complements. When $t$ increases, the firm increases $p_{i}$, so $D_{j}$ decreases, which in turn decreases $p_{j}$. However, the tax also decreases the margin from product $i$ directly, and so it becomes relatively less profitable to sell product $i$, which in turn induces the firm to increase $p_{j}$. If the latter (margin) effect dominates the former (cross-demand) effect prices are supermodular. In this case, the tax leads to positive feedback between the prices, and so the long-run pass-through is always higher than the short-run pass-through. Otherwise prices are submodular and so the tax lowers the price of the complement.

For example for linear demand and linear cost, we have $S O C_{i}=2 \partial_{p_{i}} D_{i}, S O C_{j}=2 \partial_{p_{j}} D_{j}, F B=$ $\partial_{p_{j}} D_{i}+\partial_{p_{i}} D_{j}$, and so the short-run pass-through is $1 / 2$, like the case of a single-product monopoly. If the products are complements (substitutes), then their prices are submodular (supermodular), so using Proposition 9, we show that the long-run pass-through is greater than $1 / 2$ as long as the effect of the product $j$ price on product $i$ is smaller in magnitude than the effect of product $i$ price on product $j$ demand:

Corollary 6 Consider a two-product monopoly that faces a cost shock, say excise tax $t$, only on product $i$. For linear demand and linear cost,

$$
{\frac{d p_{i}}{d t}}^{S R}=\frac{1}{2}<{\frac{d p_{i}}{d t}}^{L R} \text { if and only if }\left|\partial_{p_{i}} D_{j}\right|>\left|\partial_{p_{j}} D_{i}\right|
$$

and ${\frac{d p_{i}}{d t}}^{S R}={\frac{d p_{i}}{d t}}^{L R}=\frac{1}{2}$ if the Slutsky symmetry holds, $\partial_{p_{i}} D_{j}=\partial_{p_{j}} D_{i}$.

In cases when the Slutsky symmetry does not hold the long-run pass-through of a unit tax on product $i$ is higher if the cross-price effect from product $i$ to product $j$ is greater than the crossprice effect from product $j$ to product $i$.

Armstrong and Vickers 2015 analyze pricing by a multiproduct monopolist in a family of demand systems such that consumer surplus is homothetic in quantities, which is true, for example, for CES, linear, and Logit demands. They find that in specific cases, the elasticity of overall inverse demand is constant and that the cross pass-through rate (effect of a cost change of one product 
on the price of another) is zero, for example, for linear demand. In these specific cases Slutsky symmetry holds, that is, the cross-derivative of each demand with respect to the other product's price is the same, and so the short-run own pass-through of an idiosyncratic shock is the same as the long-run own pass-through of the shock.

\subsubsection{Two-product monopoly with one-sided effects and tax on just one of the prod- ucts}

As the results above suggest, the Slutsky symmetry is important for the cross-product pass-through rates and so whether the long-run own pass-through of the tax is higher than the short-run passthrough. For example, Slutsky symmetry is violated if consumers are not salient to $p_{j}$ when they make consumption decision for product $i: \partial_{p_{j}} D_{i}=0$ (like in Ellison 2005 when the firms do not advertise the add-on prices or in Gabaix and Laibson [2006] when all consumers are unsophisticated 25 .

Consider the special case of tax on product $i$, with the extra condition that $\partial_{p_{j}} D_{i}=0$ and with constant marginal costs. In this case a shock that changes tax on product $i$ is idiosyncratic. Since $\partial_{p_{j}} D_{i}=0, \partial_{p_{j} t}^{2} \Pi=0$. Intuitively, the shock is now idiosyncratic since the change in product $i$ 's margin due to the tax change does not have a direct effect on optimal $p_{j}$, since consumers simply do not account for it while choosing whether to buy product $i$. This case therefore corresponds to twoproduct monopoly with one-sided demand effects and idiosyncratic shock, $\beta_{i}=\beta_{j}=1, \theta=0, \gamma=0$. As a result, in this case, the pass-through of product $i$ 's tax onto $p_{j}$ is only due to feedback effects:

$$
\frac{d p_{j}}{d t}=\frac{F B \frac{\partial_{p_{i} t}^{2} \pi_{i}}{-S O C_{i}}}{-S O C_{j}-\frac{F B^{2}}{-S O C_{i}}}
$$

which illustrates that the cross-product pass-through of the tax is positive if the prices are supermodular and negative if the prices are submodular, since $\partial_{p_{i} t}^{2} \pi_{i}=-\partial_{p_{i}} D_{i}>0$ and $-S O C_{i}>0$ by our assumptions.

Corollary 7 Consider a two-product monopoly with one-sided effects, that is, $p_{j}$ is not salient to consumers when they make consumption decision for product $i$. For a unit tax on product $i$, $0<{\frac{d p_{i}}{d t}}^{S R}<{\frac{d p_{i}}{d t}}^{L R}$ as long as prices are either supermodular or submodular.

This result has important implications for tax policy. If there is a tax on the salient product, then the pass-through of this tax on the salient price is greater when the firm adjusts also the price of the non-salient product in the long run. This might sound counter-intuitive for complements, e.g., base product and add-on, since we know from the literature that the optimal price of the salient product (base product) is below its cost since the firm expects positive margin from the non-salient product (add-on) sales (see for example Gabaix and Laibson 2006]). However, the fact that the firm sells a non-salient add-on increases the own cost pass-through of the base product.

\footnotetext{
${ }^{25}$ When only some consumers are unsophisticated and ignore product $j$ price when making product $i$ consumption, the Slutsky symmetry is again violated $\left|\partial_{p_{i}} D_{j}\right|>\left|\partial_{p_{j}} D_{i}\right|$
} 
An important point is that a tax on the add-on, product $j$, is a covariant shock. A tax on product $j$ means that the add-on's margin is different, and even if $p_{j}$ is left unchanged, the firm is interested in changing $p_{i}$.

The add-on setup can be simplified even further, to a setup that is a starting point in many analyses, for example see Agarwal, Chomsisengphet, Mahoney, and Stroebel 2015. The further simplification is to assume that $D_{j}\left(p_{i}, p_{j}\right)=D_{i}\left(p_{i}\right) q_{j}\left(p_{j}\right)$, where $D_{i}\left(p_{i}\right)$ refers to the demand for the base product and $q_{j}\left(p_{j}\right)$ refers to the demand for the add-on by each customer who buys the base product. In other words, consumers first decide on product $i$, and then buy product $j$ in the amounts proportional to the demand for product $i$. With this further simplification, we have

$$
F B \equiv \partial_{p_{j} p_{i}}^{2} \Pi=D_{i}^{\prime}\left(p_{i}\right)\left[q_{j}+\left(p_{j}-t-c_{j}\right) q_{j}^{\prime}\right]=0 .
$$

The term inside the brackets is zero since the firm sets the add-on price as if it was a singleproduct monopoly. But then there is no pass-through of a base-product tax on the add-on: $\frac{d p_{j}}{d t}=0$. Intuitively, the firm is already maximizing its profit from the add-on and so will not pass-through any base-product tax onto the add-on price. In this case, the long-run pass-through of the tax onto the base-product price is the same as the short-run pass-through of the tax onto the base-product price. On the other hand, if the tax is on the add-on only, there is some cross pass-through of the tax onto the base-product price. The tax will decrease the per-customer profit from the add-on, $\pi_{j}\left(p_{j}\right)=\left(p_{j}-c_{j}-t\right) q_{j}\left(p_{j}\right)$ under standard demand forms for $q_{j}\left(p_{j}\right)$, like log-linear or linear demand. Since the firm's total profit is $\Pi=\left(p_{i}-c_{i}\right) D_{i}\left(p_{i}\right)+\pi_{j}\left(p_{j}\right) D_{i}\left(p_{i}\right)$, the per-customer profit from the add-on sales is like a cost reduction of the base product. Hence, any reduction in the add-on profits is passed onto $p_{i}$ as if it was a positive cost shock on the base product and so will increase $p_{i}$. More formally, $\frac{d p_{i}}{d c_{j}}=\frac{d p_{i}}{d c_{i}} \frac{d \pi_{j}}{d c_{j}}<0$. Hence, the tax on the add-on increases the price of the add-on as well as the price of the base product, that is, the products' prices are supermodular. But then Proposition 9 implies that the LeChatelier principle holds for a cost shock on the add-on: the long-run pass-through of the shock on the add-on price is greater than the short-run pass-through.

While this simple setup is easy to analyze, we believe that for some applications researchers might miss many of the effects we described previously for more general two-product monopoly with one-sided effects. In general the per consumer demand for add-on might depend on the base product price. This would be the case if there is correlation between the valuations for the products.

For instance, consider the case of positive correlation between the valuation for the base product and the valuation for the add-on. This happens when consumers with high willingness-to-pay for the base product are more likely to value add-on consumption higher than consumers with low willingness-to-pay for the base product. In this case, when the base product price is high, people who buy the base product have higher valuation for the add-on, on average, than in the case where the base product price is lower: base product's high price screens consumers with high valuation for add-on (like in Ellison 2005]). As a result, the add-on demand conditional on buying the base product increases in the base product price. The total add-on demand might, however, increase 
or decrease in the base product price depending on the degree of positive correlation between the valuations. Symmetrically, if there is negative correlation between the valuation for the base product and the valuation for the add-on, a high base product price screens consumers with low valuation for the add-on. As a result, the add-on demand conditional on buying the base product decreases in the base product price. The total add-on demand also decreases in the base product price. Our model of one-sided demand effects with complementarity corresponds to the situation if the total product $j$ demand decreases in product $i$ price. Our model of one-sided demand effects with substitutability correspond to the situation if the total product $j$ demand increases in product $i$ price.

\subsection{Single-product duopoly}

Let firm $i$ 's profit be $\pi_{i}\left(p_{i}, p_{j}, t\right)=\left(p_{i}-c_{i}-t\right) D_{i}\left(p_{i}, p_{j}\right)$ and firm $j$ 's profit be $\pi_{j}\left(p_{j}, p_{i}, t\right)=$ $\left(p_{i}-c_{i}-\theta t\right) D_{j}\left(p_{j}, p_{i}\right)$, where $\theta=0$ for an idiosyncratic shock (unit tax only on firm $i$ ) and $\theta=1$ for a covariant shock (industry-wide tax). This corresponds to parameter values $\beta_{i}=\beta_{j}=0, \gamma=1$ and the endogenous variables $x_{i}=p_{i}, x_{j}=p_{j}$ in the previous section model. We denote $F B_{i}=\partial_{p_{i} p_{j}}^{2} \pi_{i}$, $S O C_{i}=\partial_{p_{i} p_{i}}^{2} \pi_{i}$, and assume there exists unique and stationary equilibrium prices: $S O C_{i}<0$ and $-S O C_{i}>\left|F B_{i}\right|$. Observe that each profit, $\pi_{i}$, has increasing differences in own price, $p_{i}$, and $t$ : $\partial_{p_{i}}^{2} \pi_{i}=-\partial_{p_{i}} D_{i}>0$. The long-run and short-run pass-through of the tax are,

$$
\begin{aligned}
&{\frac{d p_{i}}{d t}}^{S R}= \frac{\partial_{p_{i} t}^{2} \pi_{i}}{-S O C_{i}}=\frac{-\partial_{p_{i}} D_{i}}{-S O C_{i}}, \\
&{\frac{d p_{i}}{d t}}^{L R}=\frac{\partial_{p_{i} t}^{2} \pi_{i}+F B_{i} \frac{\partial_{p_{j} t}^{2} \pi_{j}}{-S O C_{j}}}{-S O C_{i}-\frac{F B_{i} F B_{j}}{-S O C_{j}}}=\frac{-\partial_{p_{i}} D_{i}+F B_{i} \frac{-\theta \partial_{p_{j} D_{j}}}{-S O C_{j}}}{-S O C_{i}-\frac{F B_{i} F B_{j}}{-S O C_{j}}} .
\end{aligned}
$$

where $F B_{i}, F B_{j}>0(<0)$ if prices are supermodular (submodular).

The case of oligopoly is, in a sense, easier: a firm-specific tax shock is idiosyncratic. Intuitively, a change in my competitor's margin does not concern me unless my competitor also changes its price.

Corollary 8 Consider single-product duopoly. We have ${\frac{d p_{i}}{d t}}^{S R}<{\frac{d p_{i}}{d t}}^{L R}$

- if prices are supermodular for both firm-specific and industry-wide cost shock $t$ or

- if prices are submodular, e.g., Cournot duopoly, for only firm-specific cost shock, $\theta=0$.

Again, note that prices are supermodular for Bertrand oligopoly with linear costs. For submodular prices, we need to refer to Proposition 8 .

The principle can in general break down for submodular decisions for covariant shocks since then indirect effects have opposite sign of direct effects, or for idiosyncratic shocks more than two decisions. For the linear demand example, we have $S O C_{i}=2 \partial_{p_{i}} D_{i}, S O C_{j}=2 \partial_{p_{j}} D_{j}, F B_{i}=\partial_{p_{j}} D_{i}$, and so the short-run pass-through is $1 / 2$, like the case of a single-product monopoly. If the products are complements (substitutes), then their prices are submodular (supermodular), so we show that 
Corollary 9 Consider single-product duopoly. In the case of linear demand, we have

$$
{\frac{d p_{i}}{d t}}^{S R}=\frac{1}{2}<{\frac{d p_{i}}{d t}}^{L R}
$$

- if the firms sell substitutes, regardless of the shock being firm-specific and industry-wide or

- if the firms sell complements and the shock is firm-specific, $\theta=0$.

\subsection{Multiproduct oligopoly}

The following summarizes the implications of our general results from Section 2 and Section 3 for multiproduct firms' cost pass-through rates. Proposition 1 implies that

Corollary 10 Consider a multiproduct oligopoly that faces a tax shock. The short-run pass-through of the tax on a directly affected product's price is smaller than the long-run pass-through if each firm's profit has increasing differences in each price and the parameter and the prices are supermodular (both within firm and across firms).

Proposition 5 implies that

Corollary 11 Consider homogeneous Cournot oligopoly of multiproduct firms where a firm faces an idiosyncratic cost shock. The short-run pass-through of the tax is smaller than the long-run pass-through if each firm's profit has increasing differences in each price and the parameter, and the prices are supermodular within firm.

As expected, the case of multiproduct oligopoly effectively combines our findings from multiproduct monopoly and single-product oligopoly. These results connect to the existing theoretical marketing literature on pass-through in multiproduct oligopoly. Moorthy 2005], generalizing many of the results of Shugan and Desiraju [2001], analyzes properties of pass-through in two-player multiproduct games. Crucial assumptions in that paper are internal strategic complementarity, corresponding to our (A3'), and external strategic complementarity, corresponding to our (A4') (supermodular decisions within firm and supermodular strategic decisions across firms). Moreover, the fact that Moorthy 2005 specifically analyzes the effect of changes in marginal cost for firms with linear cost on the firms' prices, guarantees (A4) (increasing differences in parameter for all players and all strategies).

\section{Conclusion}

The LeChatelier-Samuelson principle states that when an agent experiences a shock to an exogenous parameter, the agent's short-run adjustment of a decision variable is smaller than the long-run adjustment of that variable when the other endogenous variables can also be adjusted. We characterize conditions under which the LeChatelier principle holds in non-cooperative games both for idiosyncratic shocks (that affect only one decision variable directly) and covariant shocks (that 
affect more than one decision variable directly). The short-run adjustment of a strategy involves only the directly affected strategy being adjusted, while the long-run adjustment incorporates also the adjustments of the other strategies (by the same player or by different players). We discuss examples under which the principle might be violated, and derive conditions that ensure that the principle holds.

Any (economic) model aims to capture the relationship between some variables of interest, while ignoring the changes in many other endogenous variables. For instance, in multiproduct oligopoly markets, a model of single-product duopoly ignores the fact that the duopolists also sell other related products (for example, substitutes and/or complements) and that there are other firms selling substitutes and/or complements, that impose externalities on the modeled firm's choices, for instance, positive externalities via technology spillovers or negative externalities via competition, pollution or free-riding. The LeChatelier-Samuelson principle, along with extensions in this paper and in others, shows that under certain conditions these not-modeled endogenous variables adjusting to the changes in the modeled variables generate a feedback loop of further adjustment of the modeled variables: the modeled variables should adjust to shocks more than the model predicts. Both empirical and theoretical researchers should be wary of this effect, which we extend to strategic environments.

Our results shed further light on multiproduct oligopoly cost pass-through by characterizing general conditions under which the presence of competitors and other products that each firm sells leads to higher pass-through rates. We show how the LeChatelier-Samuelson principle could provide an explanation for over-shifting of costs onto prices (cost pass-through rates of more than $100 \%$ ), which a large amount of empirical literature document and existing theories of cost passthrough cannot explain without imposing strong convexity assumptions on demand functions or strong concavity assumptions on cost functions. For example, a high level of observed cost passthrough rate does not necessarily arise from log-convex demand curves, but could instead be due to the feedback loop between the decision variables in multiproduct oligopoly markets.

An important take away from our paper is that the principle fails to hold in similar non-strategic environments: If the strategies are submodular, the principle might fail to hold for idiosyncratic shocks when there are three or more decisions or for covariant shocks when the indirect effects through other decisions outweigh the direct effect of the shock. We provide conditions for when the principle holds in both of these contexts nonetheless.

\section{References}

Sumit Agarwal, Souphala Chomsisengphet, Neale Mahoney, and Johannes Stroebel. Regulating consumer financial products: Evidence from credit cards. Quarterly Journal of Economics, 130(1):111 - 164, 2015.

Rabah Amir. Cournot oligopoly and the theory of supermodular games. Games and Economic Behavior, 15(2):132-148, 1996. 
Rabah Amir and Val E. Lambson. On the effects of entry in cournot markets. Review of economic studies, pages 235-254, 2000.

Simon P Anderson, Andre De Palma, and Brent Kreider. Tax incidence in differentiated product oligopoly. Journal of Public Economics, 81(2):173-192, 2001.

Mark Armstrong and John Vickers. Multiproduct monopoly made simple. Technical report, 2015.

José Azar, Martin C. Schmalz, and Isabel Tecu. Anti-competitive effects of common ownership. Ross School of Business Paper, (1235), 2014.

Anne-Christine Barthel and Tarun Sabarwal. Directional monotone comparative statics. Technical report, University of Kansas, Department of Economics, 2015.

Yoram Barzel. An alternative approach to the analysis of taxation. The Journal of Political Economy, pages 1177-1197, 1976.

Gary S. Becker. Crime and punishment: An economic approach. The Journal of Political Economy, 76(2):169-217, 1968.

Peter Berck, Ephraim Leibtag, Alex Solis, and Sofia Villas-Boas. Patterns of pass-through of commodity price shocks to retail prices. American journal of agricultural economics, 91(5): 1456-1461, 2009.

David Besanko, Jean-Pierre Dubé, and Sachin Gupta. Own-brand and cross-brand retail passthrough. Marketing Science, 24(1):123-137, 2005.

Timothy Besley and Harvey S. Rosen. Sales taxes and prices: an empirical analysis. National Tax Journal, 52(2):157-178, 1999.

Céline Bonnet and Vincent Réquillart. Impact of cost shocks on consumer prices in verticallyrelated markets: the case of the french soft drink market. American Journal of Agricultural Economics, 97(5):1088-1108, 2013a.

Céline Bonnet and Vincent Réquillart. Tax incidence with strategic firms in the soft drink market. Journal of Public Economics, 106:77-88, 2013b.

Jose Manuel Campa and Linda S. Goldberg. Exchange rate pass-through into import prices. Review of Economics and Statistics, 87(4):679-690, 2005.

Juan Camilo Castillo. Revising lechatelier's principle. Technical report, Stanford University, Department of Economics, https://goo.gl/YvqeGp, 2015.

Avinash Dixit. Comparative statics for oligopoly. International economic review, pages 107-122, 1986. 
Jean-Pierre Dubé and Sachin Gupta. Cross-brand pass-through in supermarket pricing. Marketing Science, 27(3):324-333, 2008.

Federico Echenique. Comparative statics by adaptive dynamics and the correspondence principle. Econometrica, pages 833-844, 2002.

Glenn Ellison. A model of add-on pricing. Quarterly Journal of Economics, 120(2):585-637, 2005.

Joseph Farrell and Carl Shapiro. Antitrust evaluation of horizontal mergers: An economic alternative to market definition. The B.E. Journal of Theoretical Economics, 10(1):Article 9, 2010.

Don Fullerton and Gilbert E. Metcalf. Tax incidence. Handbook of public economics, 4:1787-1872, 2002.

Xavier Gabaix and David Laibson. Shrouded attributes, consumer myopia, and information suppression in competitive markets. Quarterly Journal of Economics, pages 505-540, 2006.

David Genesove and Wallace P. Mullin. Testing static oligopoly models: conduct and cost in the sugar industry, 1890-1914. The RAND Journal of Economics, pages 355-377, 1998.

Pinelopi Koujianou Goldberg. Product differentiation and oligopoly in international markets: The case of the us automobile industry. Econometrica: Journal of the Econometric Society, pages 891-951, 1995.

Pinelopi Koujianou Goldberg and Frank Verboven. The evolution of price dispersion in the european car market. Review of Economic Studies, pages 811-848, 2001.

Frank H. Hahn. The stability of the cournot oligopoly solution. Review of Economic Studies, pages 329-331, 1962.

Steffen H. Hoernig. Existence of equilibrium and comparative statics in differentiated goods cournot oligopolies. International Journal of Industrial Organization, 21(7):989-1019, 2003.

Sonia Jaffe and E. Glen Weyl. The first-order approach to merger analysis. American Economic Journal: Microeconomics, 5(4):188-218, 2013.

Julian Jamison. The Le Chatelier principle in lattices. Economics Bulletin, 3(2):1-9, 2006.

Benjamin S Kay, Mark D Manuszak, and Cindy M Vojtech. Bank profitability and debit card interchange regulation: Bank responses to the durbin amendment. Available at SSRN 2449027, 2014 .

Michael Keen. The balance between specific and ad valorem taxation. Fiscal studies, 19(1):1-37, 1998.

Donald S. Kenkel. Are alcohol tax hikes fully passed through to prices? evidence from alaska. American Economic Review, pages 273-277, 2005. 
Bertrand Koebel and François Laisney. Aggregation with cournot competition: the le chatelier samuelson principle. Annals of Economics and Statistics/Annales d'Économie et de Statistique, (115-116):343-360, 2014.

Sho-Ichiro Kusumoto. Extensions of the le chatelier-samuelson principle and their application to analytical economics-constraints and economic analysis. Econometrica, pages 509-535, 1976.

George M. Lady and James P. Quirk. The global lechatelier principle and multimarket equilibria. Review of Economic Design, 14(1-2):193-201, 2010.

Paul Milgrom and John Roberts. Rationalizability, learning, and equilibrium in games with strategic complementarities. Econometrica, pages 1255-1277, 1990.

Paul Milgrom and John Roberts. The LeChatelier principle. American Economic Review, pages 173-179, 1996.

Paul Milgrom and Chris Shannon. Monotone comparative statics. Econometrica, pages 157-180, 1994.

Andrew J. Monaco and Tarun Sabarwal. Games with strategic complements and substitutes. Economic Theory, pages 1-27, 2015.

Sridhar Moorthy. A general theory of pass-through in channels with category management and retail competition. Marketing Science, 24(1):110-122, 2005.

Michio Morishima. On the laws of change of the price-system in an economy which contains complementary commodities. Osaka Economic Papers, 1(1):101-113, 1952.

William Novshek. On the existence of cournot equilibrium. The Review of Economic Studies, 52 (1):85-98, 1985 .

Daniel P. O'Brien and Steven C. Salop. Competitive effects of partial ownership: Financial interest and corporate control. Antitrust Law Journal, pages 559-614, 2000.

James M. Poterba. Retail price reactions to changes in state and local sales taxes. National Tax Journal, pages 165-176, 1996.

John K.-H. Quah. The comparative statics of constrained optimization problems. Econometrica, 75(2):401-431, 2007.

Sunanda Roy and Tarun Sabarwal. Monotone comparative statics for games with strategic substitutes. Journal of Mathematical Economics, 46(5):793-806, 2010.

Paul A. Samuelson. Foundations of economic analysis. Harvard University Press, 1947.

Paul A. Samuelson. An extension of the lechatelier principle. Econometrica, pages 368-379, 1960. 
Steven M. Shugan and Ramarao Desiraju. Retail product-line pricing strategy when costs and products change. Journal of Retailing, 77(1):17-38, 2001.

Nirvikar Singh and Xavier Vives. Price and quantity competition in a differentiated duopoly. The RAND Journal of Economics, pages 546-554, 1984.

Nicholas Stern. The effects of taxation, price control and government contracts in oligopoly and monopolistic competition. Journal of Public Economics, 32(2):133-158, 1987.

Wing Suen, Eugene Silberberg, and Paul Tseng. The lechatelier principle: the long and the short of it. Economic Theory, 16(2):471-476, 2000.

Donald M. Topkis. Minimizing a submodular function on a lattice. Operations research, 26(2): 305-321, 1978.

Xavier Vives. Nash equilibrium with strategic complementarities. Journal of Mathematical Economics, 19(3):305-321, 1990.

Xavier Vives. Oligopoly pricing: old ideas and new tools. MIT press, 2001.

E. Glen Weyl and Michal Fabinger. Pass-through as an economic tool: Principles of incidence under imperfect competition. Journal of Political Economy, 121(3):528-583, 2013.

Douglas J. Young and Agnieszka Bielińska-Kwapisz. Alcohol taxes and beverage prices. National Tax Journal, pages 57-73, 2002. 


\section{Recent ESMT Working Paper}

ESMT No.

Contracts as a barrier to entry when buyers are non-pivotal

Özlem Bedre-Defolie, ESMT European School of Management and Technology

Gary Biglaiser, University of North Carolina, Chapel Hill

What do patent-based measures tell us about product commercialization? Evidence from the pharmaceutical industry

Stefan Wagner, ESMT European School of Management and Technology

Simon Wakeman, New Zealand Productivity Commission

Hedge fund flows and performance streaks: How investors weigh information

15-01

Guillermo Baquero, ESMT European School of Management and Technology

Marno Verbeek, Rotterdam School of Management, Erasmus University

A price concentration study on European mobile telecom markets: Limitations and insights

Pauline Affeldt, E.CA Economics, ESMT European School of Management and Technology Rainer Nitsche, E.CA Economics

Two birds, one stone? Positive mood makes products seem less useful for multiplegoal pursuit

Anastasiya Pocheptsova, R. H. Smith School of Business, University of Maryland Francine Espinoza Petersen, ESMT European School of Management and Technology Jordan Etkin, Fuqua School of Business, Duke University

Contracting in medical equipment maintenance services: An empirical investigation Tian Chan, INSEAD

Francis de Véricourt, ESMT European School of Management and Technology

Omar Besbes, Columbia University

Designing luxury experience

Vadim Grigorian, Pernod Ricard

Francine Espinoza Petersen, ESMT European School of Management and Technology 